Supporting Information

Drug Discovery against Psoriasis: Identification of a New Potent FMS-like Tyrosine Kinase 3 (FLT3) Inhibitor, 1-(4-((1H-pyrazolo[3,4- $d]$ pyrimidin-4-yl)oxy) -3-fluorophenyl)-3-(5-(tert-butyl)isoxazol-3-yl)urea, That Showed Potent Activity in a Psoriatic Animal Model

Guo-Bo Li, ${ }^{\dagger}, \#$ Shuang Ma, ${ }^{\dagger}, \#$ Ling-Ling Yang, ${ }^{\dagger},{ }^{\dagger}$ Sen $\mathrm{Ji}^{\dagger}{ }^{\dagger}$ Zhen Fang, ${ }^{\dagger}$ Guo Zhang, ${ }^{\S}$ Li-Jiao Wang, ${ }^{\dagger,}$ Jie-Min Zhong, ${ }^{\dagger}$ Yu Xiong, ${ }^{\dagger}$ Jiang-Hong Wang, ${ }^{\S}$ Shen-Zhen Huang, ${ }^{\dagger}$ Lin-Li Li, ${ }^{\S}$ Rong Xiang, ${ }^{\&}$ Dawen Niu, ${ }^{\dagger}$ Ying-Chun Chen, ${ }^{\S}$ and Sheng-Yong Yang ${ }^{\dagger, *}$

${ }^{\dagger}$ State Key Laboratory of Biotherapy and Cancer Center, West China Hospital, Sichuan University/Collaborative Innovation Center of Biotherapy, Sichuan 610041, China

$\$$ College of Food and Bioengineering, Xihua University, Sichuan 610039, China

${ }^{\S}$ Key Laboratory of Drug Targeting and Drug Delivery System of Ministry of Education, West China School of Pharmacy, Sichuan University, Chengdu, Sichuan, 610041, China

${ }^{\&}$ Department of Clinical Medicine, School of Medicine, Nankai University, Tianjin, China

\# These authors contributed equally to this work.

* Corresponding to S.Y. Yang, E-mail: yangsy@,scu.edu.cn

\title{
Contents of SI
}

Supplementary methods.

Figure S1. ${ }^{1} \mathrm{H}$ NMR, ${ }^{13} \mathrm{C}$ NMR, HRMS spectra and HPLC chromatogram for compound $7 \mathbf{a}$.... S8

Figure S2. ${ }^{1} \mathrm{H} \mathrm{NMR},{ }^{13} \mathrm{C}$ NMR, HRMS spectra and HPLC chromatogram for

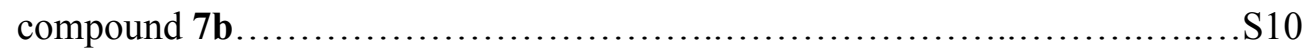

Figure S3. ${ }^{1} \mathrm{H}$ NMR and ${ }^{13} \mathrm{C}$ NMR spectra for compound $7 \mathbf{c} \ldots \ldots \ldots \ldots \ldots \ldots . . . . . . . . . . .212$

Figure S4. ${ }^{1}$ H NMR spectrum and HPLC chromatogram for compound 9a.... S13

Figure S5. ${ }^{1} \mathrm{H}$ NMR, ${ }^{13} \mathrm{C}$ NMR, HRMS spectra and HPLC chromatogram for

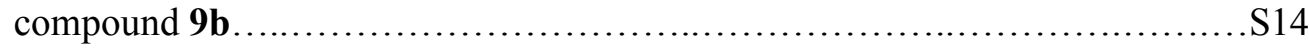

Figure S6. ${ }^{1} \mathrm{H}$ NMR, ${ }^{13} \mathrm{C}$ NMR spectra and HPLC chromatogram for compound

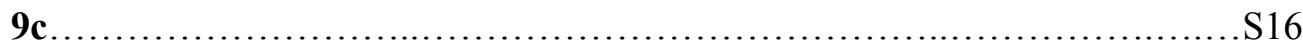

Figure S7. ${ }^{1} \mathrm{H}$ NMR spectrum and HPLC chromatogram for compound 9d.....S18

Figure S8. ${ }^{1} \mathrm{H}$ NMR spectrum and HPLC chromatogram for compound 9e......S19 
Figure S9. ${ }^{1} \mathrm{H}$ NMR spectrum and HPLC chromatogram for compound 9f.....S20

Figure S10. ${ }^{1} \mathrm{H}$ NMR, ${ }^{13} \mathrm{C}$ NMR, HRMS spectra and HPLC chromatogram for compound 12a.

Figure S11. ${ }^{1}$ H NMR, HRMS spectra and HPLC chromatogram for compound $12 b$.

Figure S12. ${ }^{1} \mathrm{H}$ NMR spectrum and HPLC chromatogram for compound 14....S25

Figure S13. ${ }^{1} \mathrm{H}$ NMR, ${ }^{13} \mathrm{C}$ NMR, HRMS spectra and HPLC chromatogram for compound 16a.

Figure S14. ${ }^{1} \mathrm{H}$ NMR, ${ }^{13} \mathrm{C}$ NMR, HRMS spectra and HPLC chromatogram for compound $16 \mathrm{~b}$ ..S28

Figure S15. ${ }^{1} \mathrm{H}$ NMR spectrum for compound 16c.. S30

Figure S16. ${ }^{1} \mathrm{H}$ NMR, ${ }^{13} \mathrm{C}$ NMR, HRMS spectra and HPLC chromatogram for compound 16d.

Figure S17. ${ }^{1} \mathrm{H}$ NMR, ${ }^{13} \mathrm{C}$ NMR, HRMS spectra and HPLC chromatogram for compound

$18 a$.

Figure S18. ${ }^{1} \mathrm{H}$ NMR, ${ }^{13} \mathrm{C}$ NMR, HRMS spectra and HPLC chromatogram for compound $\mathbf{1 8 b}$.

Figure S19. ${ }^{1} \mathrm{H}$ NMR, ${ }^{13} \mathrm{C}$ NMR, HRMS spectra and HPLC chromatogram for compound 18c.

Figure S20. ${ }^{1} \mathrm{H}$ NMR, ${ }^{13} \mathrm{C}$ NMR, HRMS spectra and HPLC chromatogram for compound 18d.

Figure S21. ${ }^{1} \mathrm{H}$ NMR, ${ }^{13} \mathrm{C}$ NMR, HRMS spectra and HPLC chromatogram for compound 18e

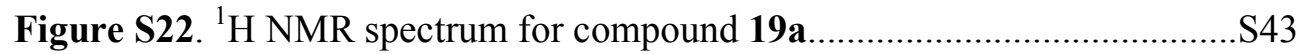

Figure S23. ${ }^{1} \mathrm{H}$ NMR and ${ }^{13} \mathrm{C}$ NMR spectra for compound 19b......................S44

Figure S24. ${ }^{1} \mathrm{H}$ NMR, ${ }^{13} \mathrm{C}$ NMR, HRMS spectra and HPLC chromatogram for

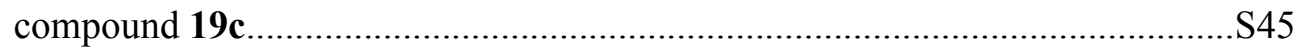

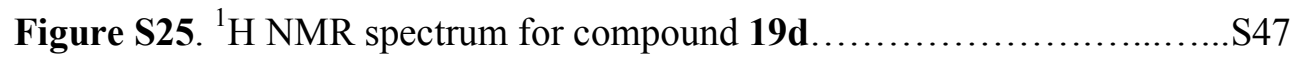

Figure S26. ${ }^{1} \mathrm{H}$ NMR spectrum for compound 20........................S48 


\section{Supplementary Methods}

1-(4-(1H-pyrazolo[3,4-d]pyrimidin-4-yloxy)phenyl)-3-(5-(trifluoromethyl)iso xazol-3-yl)urea (7c) 5-(Trifluoromethyl)isoxazol-3-amine (4c) was synthesized from 4,4,4-trifluoro-3-oxobutanenitrile (3b) and hydroxylamine hydrochloride using a procedure similar to that for $4 \mathbf{a}$. Yield: $24 \%$.

The title compound was synthesized in a manner similar to the synthesis of $7 \mathbf{a}$ using compounds $\mathbf{4 c}$ and $\mathbf{6}$ to give compound $\mathbf{7 c}$, which was purified by column chromatography (eluent gradient $\mathrm{CH}_{2} \mathrm{Cl}_{2}: \mathrm{MeOH}, 60: 1$ ) and recrystallized from EtOAc and petroleum ether. Yield: 58\%, 95.1\% HPLC purity. ${ }^{1} \mathrm{H}$ NMR (400 MHz, DMSO- $\left.d_{6}\right): \delta 14.15(\mathrm{~s}, 1 \mathrm{H}), 10.90(\mathrm{~s}, 1 \mathrm{H}), 9.19(\mathrm{~s}, 1 \mathrm{H}), 8.51(\mathrm{~s}, 1 \mathrm{H}), 8.08(\mathrm{~s}, 1 \mathrm{H})$, 7.59 (d, $J=8.8 \mathrm{~Hz}, 2 \mathrm{H}), 7.30$ (d, $J=8.8 \mathrm{~Hz}, 2 \mathrm{H}), 6.52(\mathrm{~s}, 1 \mathrm{H}) \mathrm{ppm} ;{ }^{13} \mathrm{C}$ NMR $(100$ $\left.\mathrm{MHz}, \mathrm{DMSO}-d_{6}\right): \delta 182.2,163.6,158.8,157.2,155.4,151.9,147.3,137.2,132.3$, 127.8, 122.8, 120.2, 101.8, 93.0 ppm; LC-MS m/z: 406.1 [M+ H] $]^{+}$

1-(4-(1H-pyrazolo[3,4-d]pyrimidin-4-yloxy)phenyl)-3-(3-tert-butyl-1-methyl$1 \boldsymbol{H}$-pyrazol-5-yl)urea (9a) 3-(Tert-butyl)-1-methyl-1 $H$-pyrazol-5-amine (8a) was synthesized from the reaction of 4,4-dimethyl-3-oxopentanenitrile (3a) and methylhydrazine in alcohol at $90{ }^{\circ} \mathrm{C}$ for 7 hours. Yield: $84 \%$.

The title compound was synthesized in a manner similar to the synthesis of $7 \mathbf{a}$ using compounds 8a and $\mathbf{6}$ to give compound 9a, which was purified by column chromatography (eluent gradient $\mathrm{CH}_{2} \mathrm{Cl}_{2}: \mathrm{MeOH}, 50: 1$ ) and recrystallized from EtOAc and petroleum. Yield: 74\%, 95.6\% HPLC purity. ${ }^{1} \mathrm{H}$ NMR (400 MHz, DMSO- $\left.d_{6}\right): \delta$ 14.13 (s, 1H), 9.03 (br s, 1H), $8.54(\mathrm{~s}, 1 \mathrm{H}), 8.51$ (s, 1H), 8.03 (s, 1H), 7.56 (d, J=8.0 $\mathrm{Hz}, 2 \mathrm{H}), 7.25$ (d, J=8.0 Hz, 2H), 6.06 (s, 1H), 3.62 (s, 3H), 1.22 (s, 9H) ppm; LC-MS $\mathrm{m} / \mathrm{z}: 407.1[\mathrm{M}+\mathrm{H}]^{+}$.

5-(3-(4-(1H-pyrazolo[3,4-d]pyrimidin-4-yloxy)phenyl)ureido)-3-tert-butyl-1 $\boldsymbol{H}$-pyrazole-1-carboxylic acid (9c) Tert-butyl 5-amino-3-(tert-butyl)-1 $H$-pyrazole1-carboxylate (8c) was synthesized from 4,4-dimethyl-3-oxopentanenitrile (3a) and tert-butyl hydrazine carboxylate using a procedure similar to that used to synthesize 8a. Yield: $72 \%$.

The title compound was synthesized in a manner similar to the synthesis of $7 \mathbf{a}$ using compound $8 \mathbf{c}$ and $\mathbf{6}$ to give compound $9 \mathbf{c}$, which was purified by column chromatography (eluent gradient $\mathrm{CH}_{2} \mathrm{Cl}_{2}: \mathrm{MeOH}, 45: 1$ ) and recrystallized from EtOAc and petroleum ether. Yield: 70\%, 95.5\% HPLC purity. ${ }^{1} \mathrm{H}$ NMR (400 MHz, DMSO-d $\left.d_{6}\right): \delta 14.12(\mathrm{~s}, 1 \mathrm{H}), 11.99(\mathrm{~s}, 1 \mathrm{H}), 9.34(\mathrm{~s}, 1 \mathrm{H}), 8.95(\mathrm{~s}, 1 \mathrm{H}), 8.51(\mathrm{~s}, 1 \mathrm{H})$, $8.02(\mathrm{~s}, 1 \mathrm{H}), 7.54(\mathrm{~d}, J=8.8 \mathrm{~Hz}, 2 \mathrm{H}), 7.24(\mathrm{~d}, J=8.8 \mathrm{~Hz}, 2 \mathrm{H}), 6.00(\mathrm{~s}, 1 \mathrm{H}), 1.25(\mathrm{~s}, 9 \mathrm{H})$ ppm; ${ }^{13} \mathrm{C}$ NMR (100 MHz, DMSO- $\left.d_{6}\right): \delta 163.7,157.2,155.5,153.3,152.6,145.9$, 138.1, 132.3, 122.8, 120.8, 119.8, 115.7, 101.8, 91.3, 31.1, 30.4 ppm; HRMS (m/z): calcd for $\mathrm{C}_{20} \mathrm{H}_{21} \mathrm{~N}_{8} \mathrm{O}_{4}[\mathrm{M}+\mathrm{H}]^{+}$437.2383, found 437.2381.

1-(4-(1H-pyrazolo[3,4-d]pyrimidin-4-yloxy)phenyl)-3-(3-tert-butyl-1-phenyl1H-pyrazol-5-yl)urea (9d) 3-(Tert-butyl)-1-phenyl-1H-pyrazol-5-amine (8d) was synthesized from 4,4-dimethyl-3-oxopentanenitrile (3a) and phenylhydrazine using a procedure similar to that used for 8 a. Yield: $81 \%$.

The title compound was synthesized in a manner similar to the synthesis of $7 \mathbf{a}$ using compounds 8d and $\mathbf{6}$ to give compound 9d, which was purified by column 
chromatography (eluent gradient $\mathrm{CH}_{2} \mathrm{Cl}_{2}: \mathrm{MeOH}, 50: 1$ ) and recrystallized from EtOAc and petroleum ether. Yield: 86\%, 96.4\% HPLC purity. ${ }^{1} \mathrm{H}$ NMR (400 MHz, DMSO-d $\left.d_{6}\right): \delta 14.14(\mathrm{~s}, 1 \mathrm{H}), 9.16(\mathrm{~s}, 1 \mathrm{H}), 8.50(\mathrm{~s}, 1 \mathrm{H}), 8.45(\mathrm{~s}, 1 \mathrm{H}), 8.03(\mathrm{~s}, 1 \mathrm{H})$, 7.55-7.50 (m, 6H), 7.44-7.41 (m, 1H), $7.23(\mathrm{~d}, J=9.2 \mathrm{~Hz}, 2 \mathrm{H}), 6.40(\mathrm{~s}, 1 \mathrm{H}), 1.30$ (s, 9H) ppm; ${ }^{13} \mathrm{C}$ NMR (100 MHz, DMSO- $\left.d_{6}\right): \delta 163.8,158.6,157.2,154.9,152.2$, $146.8,140.1,138.3,132.3,129.8,126.3,125.0,122.8,120.8,119.8,115.7,101.8$, 91.3, 31.1, 30.4 ppm; HRMS (m/z): calcd for $\mathrm{C}_{25} \mathrm{H}_{24} \mathrm{~N}_{8} \mathrm{O}_{2}[\mathrm{M}+\mathrm{H}]^{+} 469.2022$, found 469.2020.

1-(4-(1H-pyrazolo[3,4-d]pyrimidin-4-yloxy)phenyl)-3-(1-methyl-3-(trifluoro methyl)-1H-pyrazol-5-yl)urea (9e) 1-Methyl-3-(trifluoromethyl)-1H-pyrazol-5amine (8e) was synthesized from 4,4,4-trifluoro-3-oxobutanenitrile (3b) and methylhydrazine using a procedure similar to that for $\mathbf{8 a}$. Yield: $68 \%$.

The title compound was synthesized in a manner similar to the synthesis of $\mathbf{7 a}$ using compounds $8 \mathbf{e}$ and $\mathbf{6}$ to give compound $9 \mathbf{e}$, which was purified by column chromatography (eluent gradient $\mathrm{CH}_{2} \mathrm{Cl}_{2}: \mathrm{MeOH}, 50: 1$ ) and recrystallized from EtOAc and petroleum ether. Yield: 77\%, 98.9\% HPLC purity. ${ }^{1} \mathrm{H}$ NMR $(400 \mathrm{MHz}$, DMSO-d $\left.d_{6}\right): \delta 14.15(\mathrm{~s}, 1 \mathrm{H}), 9.19(\mathrm{~s}, 1 \mathrm{H}), 9.13(\mathrm{br} \mathrm{s}, 1 \mathrm{H}), 8.51(\mathrm{~s}, 1 \mathrm{H}), 8.06(\mathrm{~s}, 1 \mathrm{H})$, 7.57 (d, $J=8.8 \mathrm{~Hz}, 2 \mathrm{H}), 7.27$ (d, $J=8.8 \mathrm{~Hz}, 2 \mathrm{H}), 6.63(\mathrm{~s}, 1 \mathrm{H}), 3.79$ (s, 3H) ppm; LC-MS m/z: $419.1[\mathrm{M}+\mathrm{H}]^{+}$.

1-(4-(1H-pyrazolo[3,4-d]pyrimidin-4-yloxy)phenyl)-3-(3-isopropyl-1-methyl1H-pyrazol-5-yl)urea (9f) 3-Isopropyl-1-methyl-1H-pyrazol-5-amine (8f) was synthesized from 4-methyl-3-oxopentanenitrile (3c) and methylhydrazine using a procedure similar to that of $8 \mathbf{a}$. Yield: $55 \%$.

The title compound was synthesized in a manner similar to the synthesis of $\mathbf{7 a}$ using compounds $8 \mathrm{f}$ and $\mathbf{6}$ to give compound 9f, which was purified by column chromatography (eluent gradient $\mathrm{CH}_{2} \mathrm{Cl}_{2}: \mathrm{MeOH}, 50: 1$ ) and recrystallized from EtOAc and petroleum ether. Yield: 58\%, 95.6\% HPLC purity. ${ }^{1} \mathrm{H}$ NMR $(400 \mathrm{MHz}$, DMSO- $\left.d_{6}\right): \delta 14.12(\mathrm{~s}, 1 \mathrm{H}), 9.01(\mathrm{~s}, 1 \mathrm{H}), 8.55(\mathrm{~s}, 1 \mathrm{H}), 8.50(\mathrm{~s}, 1 \mathrm{H}), 8.02(\mathrm{~s}, 1 \mathrm{H}), 7.56$ $(\mathrm{d}, J=8.8 \mathrm{~Hz}, 2 \mathrm{H}), 7.25(\mathrm{~d}, J=8.8 \mathrm{~Hz}, 2 \mathrm{H}), 6.02(\mathrm{~s}, 1 \mathrm{H}), 3.61(\mathrm{~s}, 3 \mathrm{H}), 2.71-2.82(\mathrm{~m}$, $1 \mathrm{H}), 1.17(\mathrm{~d}, J=8.0 \mathrm{~Hz}, 6 \mathrm{H}) \mathrm{ppm} ;{ }^{13} \mathrm{C}$ NMR (100 MHz, DMSO- $\left.d_{6}\right): \delta 164.1,158.3$, $155.5,153.0,152.1,146.3,138.1,132.3,122.0,120.8,119.2,115.8,101.3,92.3,35.8$, 26.3, 20.4 ppm; LC-MS m/z: $393.2[\mathrm{M}+\mathrm{H}]^{+}$.

1-(4-(1H-pyrazolo[3,4-d]pyrimidin-4-yloxy)phenyl)-3-(4-phenylthiazol-2-yl)u

rea (12b) 4-Phenylthiazol-2-amine (11b) was synthesized from 2-bromo-1-phenylethanone (10b) and thiocarbamide using a procedure similar to that for 11a. Yield: $75 \%$.

The title compound was synthesized in a manner similar to the synthesis of $7 \mathbf{a}$ using compounds 11b and $\mathbf{6}$ to give compound $\mathbf{1 2 b}$, which was purified by column chromatography (eluent gradient $\mathrm{CH}_{2} \mathrm{Cl}_{2}: \mathrm{MeOH}, 45: 1$ ) and recrystallized from EtOAc and petroleum ether. Yield: 71\%, 95.5\% HPLC purity. ${ }^{1} \mathrm{H}$ NMR (400 MHz, DMSO-d $\left.d_{6}\right): \delta 14.14(\mathrm{~s}, 1 \mathrm{H}), 10.76(\mathrm{~s}, 1 \mathrm{H}), 9.06(\mathrm{~s}, 1 \mathrm{H}), 8.51(\mathrm{~s}, 1 \mathrm{H}), 8.06(\mathrm{~s}, 1 \mathrm{H})$, 7.90 (d, $J=8.8 \mathrm{~Hz}, 2 \mathrm{H}), 7.60(\mathrm{~d}, J=8.8 \mathrm{~Hz}, 2 \mathrm{H}), 7.56(\mathrm{~s}, 1 \mathrm{H}), 7.43(\mathrm{t}, J=8.0 \mathrm{~Hz}, 2 \mathrm{H})$, 7.34-7.29 (m, 3H) ppm; ${ }^{13} \mathrm{C}$ NMR (100 MHz, DMSO- $\left.d_{6}\right): \delta 168.4,163.2,158.3$, $155.5,153.0,152.1,146.3,138.1,132.3,129.0,125.9,122.0,120.8,119.8,118.3$, 
115.8, 101.3 ppm; HRMS (m/z): calcd for $\mathrm{C}_{21} \mathrm{H}_{16} \mathrm{~N}_{7} \mathrm{O}_{2} \mathrm{~S}[\mathrm{M}+\mathrm{H}]^{+}$430.1081, found 430.1078; $\mathrm{C}_{21} \mathrm{H}_{16} \mathrm{~N}_{7} \mathrm{NaO}_{2} \mathrm{~S}[\mathrm{M}+\mathrm{Na}]^{+}$452.0900, found 452.0897 .

1-(4-(1H-pyrazolo[3,4-d]pyrimidin-4-yloxy)phenyl)-3-(benzo[d]thiazol-2-yl)u rea (14) The title compound was synthesized in a manner similar to the synthesis of 7a using compounds 13 and 6to give compound 14, which was purified by column chromatography (eluent gradient $\mathrm{CH}_{2} \mathrm{Cl}_{2}: \mathrm{MeOH}, 50: 1$ ) and recrystallized from EtOAc and petroleum ether. Yield: 43\%, 97.7\% HPLC purity. ${ }^{1} \mathrm{H}$ NMR(400 MHz, DMSO-d $\left.d_{6}\right): \delta 14.14(\mathrm{~s}, 1 \mathrm{H}), 10.85(\mathrm{~s}, 1 \mathrm{H}), 9.33(\mathrm{~s}, 1 \mathrm{H}), 8.52(\mathrm{~s}, 1 \mathrm{H}), 8.07(\mathrm{~s}, 1 \mathrm{H})$, 7.91 (d, $J=7.2 \mathrm{~Hz}, 1 \mathrm{H}), 7.64$ (d, $J=8.4 \mathrm{~Hz}, 3 \mathrm{H}), 7.40$ (t, $J=7.6 \mathrm{~Hz}, 1 \mathrm{H}), 7.30$ (d, $J=8.8$ $\mathrm{Hz}, 2 \mathrm{H}), 7.25$ (t, $J=8.0 \mathrm{~Hz}, 1 \mathrm{H}) \mathrm{ppm}$; LC-MS m/z: $404.1[\mathrm{M}+\mathrm{H}]^{+}$.

1-(5-Tert-bylisoxazol-3-yl)-3-(4-(1-methyl-1H-pyrazolo[3,4-d]pyrimidin-4-yl oxy)phenyl)urea (16a) A suspension of compound 7a $(0.786 \mathrm{~g}, 2.0 \mathrm{mmol})$ and sodium hydroxide $(0.08 \mathrm{~g}, 2.0 \mathrm{mmol})$ in dry DMF $(10 \mathrm{ml})$ was stirred at room temperature for 30 minutes. Iodomethane $(0.15 \mathrm{ml}, 2.4 \mathrm{mmol})$ was added and the resulting mixture was stirred overnight. The reaction mixture was then treated with water $(100 \mathrm{ml})$ and extracted with EtOAc $(3 \times 60 \mathrm{~mL})$. The combined organic layers were removed in vacuo. The residue obtained was purified by column chromatography (eluent gradient petroleum ether:EtOAc, 2:1) and recrystallized from EtOAc and petroleum ether to provide $16 \mathrm{a}(0.49 \mathrm{~g}$, Yield: $61 \%, 95.0 \%$ HPLC purity). ${ }^{1} \mathrm{H}$ NMR (400 MHz, DMSO- $\left.d_{6}\right): \delta 9.57(\mathrm{~s}, 1 \mathrm{H}), 8.95(\mathrm{~s}, 1 \mathrm{H}), 8.55(\mathrm{~s}, 1 \mathrm{H}), 8.08(\mathrm{~s}$, 1H), 7.56 (d, $J=8.8 \mathrm{~Hz}, 2 \mathrm{H}), 7.27$ (d, $J=8.8 \mathrm{~Hz}, 2 \mathrm{H}), 6.52$ (s, 1H), 4.05 (s, 3H), 1.30 (s, 9H) ppm; ${ }^{13} \mathrm{C}$ NMR (100 MHz, DMSO- $\left.d_{6}\right): \delta 180.6,163.6,162.7,158.8,155.3$, 151.9, 147.3, 137.4, 131.2, 122.7, 120.2, 102.2, 92.9, 34.4, 32.9, 28.8 ppm; HRMS (m/z): calcd for $\mathrm{C}_{20} \mathrm{H}_{22} \mathrm{~N}_{7} \mathrm{O}_{3}[\mathrm{M}+\mathrm{H}]^{+} 408.1779$, found 408.1768; $\mathrm{C}_{20} \mathrm{H}_{21} \mathrm{~N}_{7} \mathrm{NaO}_{3}[\mathrm{M}$ $+\mathrm{Na}]^{+} 430.1598$, found 430.1595 .

1-(5-Tert-butylisoxazol-3-yl)-3-(4-(1-isopropyl-1 H-pyrazolo[3,4-d]pyrimidin -4-yloxy)phenyl)urea (16b) A suspension of compound 7a $(0.786 \mathrm{~g}, 2.0 \mathrm{mmol})$ and sodium hydroxide $(0.08 \mathrm{~g}, 2.0 \mathrm{mmol})$ in dry DMF $(10 \mathrm{ml})$ was stirred at room temperature for 30 minutes. 2-Bromopropane $(0.246 \mathrm{~g}, 2.4 \mathrm{mmol})$ was added, and the resulting mixture was warmed to $60{ }^{\circ} \mathrm{C}$ for $4 \mathrm{~h}$. The reaction mixture was then treated with water $(100 \mathrm{ml})$ and extracted with EtOAc $(3 \times 60 \mathrm{~mL})$. The combined organic layers were removed in vacuo, and the residue obtained was purified by column chromatography (eluent gradient $\mathrm{CH}_{2} \mathrm{Cl}_{2}: \mathrm{MeOH}, 90: 1$ ) and recrystallized from EtOAc and petroleum ether to provide 16b $(0.818 \mathrm{~g}$, Yield: 94\%, 96.6\% HPLC purity). ${ }^{1} \mathrm{H}$ NMR (400 MHz, DMSO- $\left.d_{6}\right): \delta 9.44$ (br s, $\left.1 \mathrm{H}\right), 8.94(\mathrm{~s}, 1 \mathrm{H}), 8.53(\mathrm{~s}, 1 \mathrm{H})$, $8.05(\mathrm{~s}, 1 \mathrm{H}), 7.56(\mathrm{~d}, J=9.2 \mathrm{~Hz}, 2 \mathrm{H}), 7.27$ (d, $J=8.8 \mathrm{~Hz}, 2 \mathrm{H}), 6.51(\mathrm{~s}, 1 \mathrm{H}), 5.16-5.11$ $(\mathrm{m}, 1 \mathrm{H}), 1.51(\mathrm{~d}, J=4.0 \mathrm{~Hz}, 6 \mathrm{H}), 1.30(\mathrm{~s}, 9 \mathrm{H}) \mathrm{ppm} ;{ }^{13} \mathrm{C}$ NMR (100 MHz, DMSO- $\left.d_{6}\right)$ : $\delta 180.6,163.7,158.9,155.1,154.4,152.0,147.2,137.5,131.2,122.8,120.1,102.4$, 93.0, 49.5, 32.9, 28.8, $22.2 \mathrm{ppm}$; HRMS (m/z): calcd for $\mathrm{C}_{22} \mathrm{H}_{26} \mathrm{~N}_{7} \mathrm{O}_{3}[\mathrm{M}+\mathrm{H}]^{+}$ 436.2092, found 436.2084; $\mathrm{C}_{22} \mathrm{H}_{25} \mathrm{~N}_{7} \mathrm{NaO}_{3}[\mathrm{M}+\mathrm{Na}]^{+}$458.1911, found 458.1912.

\section{1-(5-Tert-butylisoxazol-3-yl)-3-(4-(1-(3-(dimethylamino)propyl)-1H-pyrazolo} $[3,4-d]$ pyrimidin-4-yloxy)phenyl)urea (16c) A suspension of compound 6 (1.13 g, $5.0 \mathrm{mmol})$ and sodium hydroxide $(0.2 \mathrm{~g}, 5.0 \mathrm{mmol})$ in dry DMF $(15 \mathrm{ml})$ was stirred at room temperature for 30 minutes. 3-Chloro- $N, N$-dimethylpropan-1-amine $(0.91 \mathrm{~g}, 7.5$ 
mmol) and $\mathrm{K}_{2} \mathrm{CO}_{3}(0.69 \mathrm{~g}, 5.0 \mathrm{mmol})$ were then added, and the resulting mixture was warmed to $100{ }^{\circ} \mathrm{C}$ for $4 \mathrm{~h}$. The reaction mixture was then treated with water $(100 \mathrm{ml})$ and extracted with EtOAc $(3 \times 60 \mathrm{~mL})$. The combined organic layers were removed in vacuo, and the residue obtained was purified by column chromatography (eluent gradient $\left.\mathrm{CH}_{2} \mathrm{Cl}_{2}: \mathrm{MeOH}, 20: 1\right)$ and recrystallized from EtOAc and petroleum ether to provide 15a (1.40 g, Yield: 90\%). ${ }^{1} \mathrm{H}$ NMR (400 MHz, DMSO- $\left.d_{6}\right): \delta 8.53(\mathrm{~s}, 1 \mathrm{H})$, $7.69(\mathrm{~s}, 1 \mathrm{H}), 6.96(\mathrm{~d}, J=8.4 \mathrm{~Hz}, 2 \mathrm{H}), 6.64(\mathrm{~d}, J=8.4 \mathrm{~Hz}, 2 \mathrm{H}), 5.19$ (s, 2H) , 4.43 (t, $J=6.8 \mathrm{~Hz}, 2 \mathrm{H}), 2.24$ (t, $J=7.6 \mathrm{~Hz}, 2 \mathrm{H}), 2.12$ (s, 6H), 1.97 (t, $J=7.6 \mathrm{~Hz}, 2 \mathrm{H}) \mathrm{ppm}$.

The title compound was synthesized in a manner similar to the synthesis of $7 \mathbf{a}$ using compounds 15a and 4a to give compound 16c, which was purified by column chromatography (eluent gradient $\mathrm{CH}_{2} \mathrm{Cl}_{2}: \mathrm{MeOH}, 25: 1$ ) and recrystallized from EtOAc and petroleum ether. Yield: 74\%, 98.2\% HPLC purity. ${ }^{1} \mathrm{H}$ NMR (400 MHz, DMSO- $\left.d_{6}\right): \delta 9.77(\mathrm{~s}, 1 \mathrm{H}), 9.59(\mathrm{~s}, 1 \mathrm{H}), 8.57(\mathrm{~s}, 1 \mathrm{H}), 8.11(\mathrm{~s}, 1 \mathrm{H}), 7.58(\mathrm{~d}, J=8.8 \mathrm{~Hz}$, $2 \mathrm{H}), 7.26(\mathrm{~d}, J=8.8 \mathrm{~Hz}, 2 \mathrm{H}), 6.52(\mathrm{~s}, 1 \mathrm{H}), 4.52(\mathrm{t}, J=6.4 \mathrm{~Hz}, 2 \mathrm{H}), 2.98(\mathrm{t}, J=7.6 \mathrm{~Hz}$, $2 \mathrm{H}), 2.64(\mathrm{~s}, 6 \mathrm{H}), 2.24(\mathrm{t}, J=7.6 \mathrm{~Hz}, 2 \mathrm{H}), 1.30(\mathrm{~s}, 9 \mathrm{H}) \mathrm{ppm} ;{ }^{13} \mathrm{C}$ NMR $(100 \mathrm{MHz}$, DMSO- $\left.d_{6}\right): \delta 179.5,162.8,158.1,156.5,154.3,151.1,146.9,136.8,131.8,122.3$, $119.7,101.3,92.4,55.6,48.2,47.9,31.2,30.1,27.5$ ppm; LC-MS m/z: $479.2[\mathrm{M}+$ $\mathrm{H}]^{+}$.

1-(4-(1H-pyrazolo[3,4-d]pyrimidin-4-yloxy)-2-methylphenyl)-3-(5-tert-butyli soxazol-3-yl)urea (18d) The title compound was synthesized in a manner similar to the synthesis of $\mathbf{7 a}$ using compounds $\mathbf{1 7} \mathbf{d}$ and $\mathbf{4 a}$ to give compound $\mathbf{1 8 d}$, which was purified by column chromatography (eluent gradient $\mathrm{CH}_{2} \mathrm{Cl}_{2}: \mathrm{MeOH}, 90: 1$ ) and recrystallized from EtOAc and petroleum ether. Yield: 56\%, 96.8\% HPLC purity. ${ }^{1} \mathrm{H}$ NMR (400 MHz, DMSO- $\left.d_{6}\right)$ : $\delta 14.13(\mathrm{~s}, 1 \mathrm{H}), 9.89(\mathrm{~s}, 1 \mathrm{H}), 8.51(\mathrm{~s}, 1 \mathrm{H}), 8.35(\mathrm{~s}, 1 \mathrm{H})$, $8.04(\mathrm{~s}, 1 \mathrm{H}), 7.91$ (d, $J=8.8 \mathrm{~Hz}, 1 \mathrm{H}), 7.20(\mathrm{~s}, 1 \mathrm{H}), 7.13(\mathrm{~d}, J=6.0 \mathrm{~Hz}, 1 \mathrm{H}), 6.47$ (s, 1H), $2.28(\mathrm{~s}, 3 \mathrm{H}), 1.30(\mathrm{~s}, 9 \mathrm{H}) \mathrm{ppm} ;{ }^{13} \mathrm{C}$ NMR $\left(100 \mathrm{MHz}, \mathrm{DMSO}-d_{6}\right): \delta 180.7,163.8$, $159.0,157.1,155.4,152.1,147.9,135.2,132.0,130.5,123.9,122.8,120.0,101.8$, 92.8, 32.9, 28.8, 19.0 ppm; HRMS (m/z): calcd for $\mathrm{C}_{20} \mathrm{H}_{22} \mathrm{~N}_{7} \mathrm{O}_{3}[\mathrm{M}+\mathrm{H}]^{+}$408.1779, found 408.1780; $\mathrm{C}_{20} \mathrm{H}_{21} \mathrm{~N}_{7} \mathrm{NaO}_{3}[\mathrm{M}+\mathrm{Na}]^{+} 430.1598$, found 430.1608 .

1-(4-(1H-pyrazolo[3,4-d]pyrimidin-4-yloxy)-3-fluorophenyl)-3-(3-tert-butyl1-methyl-1H-pyrazol-5-yl)urea (19a) The title compound was synthesized in a manner similar to the synthesis of $\mathbf{7 a}$ using compounds $\mathbf{1 7} \mathbf{b}$ and $\mathbf{8 a}$ to give compound 19a, which was purified by column chromatography (eluent gradient $\mathrm{CH}_{2} \mathrm{Cl}_{2}: \mathrm{MeOH}$, 65:1) and recrystallized from EtOAc and petroleum ether. Yield: 73\%, 96.2\% HPLC purity. ${ }^{1} \mathrm{H}$ NMR (400 MHz, DMSO- $\left.d_{6}\right): \delta 14.24(\mathrm{~s}, 1 \mathrm{H}), 9.21(\mathrm{~s}, 1 \mathrm{H}), 8.61(\mathrm{~s}, 1 \mathrm{H})$, $8.52(\mathrm{~s}, 1 \mathrm{H}), 8.31(\mathrm{~s}, 1 \mathrm{H}), 7.68(\mathrm{~d}, J=8.0 \mathrm{~Hz}, 1 \mathrm{H}), 7.38(\mathrm{t}, J=8.0 \mathrm{~Hz} 1 \mathrm{H}), 7.24(\mathrm{~d}$, $J=8.0 \mathrm{~Hz}, 1 \mathrm{H}), 6.07(\mathrm{~s}, 1 \mathrm{H}), 3.62(\mathrm{~s}, 3 \mathrm{H}), 1.22$ (s, 9H) ppm; ${ }^{13} \mathrm{C}$ NMR (100 MHz, DMSO- $\left.d_{6}\right): \delta 180.2,162.3,159.1,157.6,155.5,152.8,151.9,138.2,133.9,132.2$, 124.4, 115.3, 107.4, 101.0, 93.4, 38.0, 33.0, 28.8 ppm; LC-MS m/z: $425.2[\mathrm{M}+\mathrm{H}]^{+}$.

1-(4-(1H-pyrazolo[3,4-d]pyrimidin-4-yloxy)-3-fluorophenyl)-3-(3-tert-butyl1-(4-fluorophenyl)-1H-pyrazol-5-yl)urea (19d) The title compound was synthesized

in a manner similar to the synthesis of $\mathbf{7 a}$ using compound $\mathbf{1 7 b}$ and 3-tert-butyl-1-(4-fluorophenyl)-5-isocyanato-1 $H$-pyrazole to give compound 19d, which was purified by column chromatography (eluent gradient $\mathrm{CH}_{2} \mathrm{Cl}_{2}: \mathrm{MeOH}, 65: 1$ ) 
and recrystallized from EtOAc and petroleum ether. Yield: 79\%, 97.5\% HPLC purity. ${ }^{1} \mathrm{H}$ NMR (400 MHz, DMSO- $\left.d_{6}\right): \delta 14.23$ (s, 1H), 9.29 (s, 1H), 8.51 (s, 1H), 8.49 (s, $1 \mathrm{H}), 8.30(\mathrm{~s}, 1 \mathrm{H}), 7.65-7.56(\mathrm{~m}, 3 \mathrm{H}), 7.38(\mathrm{t}, J=8.8 \mathrm{~Hz}, 3 \mathrm{H}), 7.18(\mathrm{~d}, J=8.8 \mathrm{~Hz}, 1 \mathrm{H})$, $6.38(\mathrm{~s}, 1 \mathrm{H}), 1.29(\mathrm{~s}, 9 \mathrm{H}) \mathrm{ppm} ;{ }^{13} \mathrm{C}$ NMR $\left(100 \mathrm{MHz}, \mathrm{DMSO}-d_{6}\right): \delta 180.8,164.3$, $162.8,158.4,157.9,155.6,152.8,139.5,138.2,135.3,133.5,132.2,124.7,120.0$, 119.4, 114.9, 107.0, 101.4, 95.2, 32.4, 30.9 ppm; LC-MS m/z:505.2 [M + H] ${ }^{+}$.

1-(4-(1H-pyrazolo[3,4-d]pyrimidin-4-yloxy)-3-fluorophenyl)-3-(1-methyl-3-(t rifluoromethyl)-1H-pyrazol-5-yl)urea (20) The title compound was synthesized in a manner similar to the synthesis of $\mathbf{7 a}$ using compounds $\mathbf{1 7} \mathbf{b}$ and $\mathbf{8 e}$ to give compound 20, which was purified by column chromatography (eluent gradient $\mathrm{CH}_{2} \mathrm{Cl}_{2}: \mathrm{MeOH}$, 55:1) and recrystallized from EtOAc and petroleum ether. Yield: 56\%, 98.0\% HPLC purity. ${ }^{1} \mathrm{H}$ NMR (400 MHz, DMSO- $d_{6}$ ): $\delta 14.23$ (s, 1H), 9.41 (s, 1H), 9.13 (br s, 1H), $8.53(\mathrm{~s}, 1 \mathrm{H}), 8.33(\mathrm{~s}, 1 \mathrm{H}), 7.69$ (d, $J=12.8 \mathrm{~Hz}, 1 \mathrm{H}), 7.41(\mathrm{t}, J=8.8 \mathrm{~Hz}, 1 \mathrm{H}), 7.28$ (d, $J=8.8 \mathrm{~Hz}, 1 \mathrm{H}), 6.64$ (s, 1H), 3.79 (s, 3H) ppm; LC-MS m/z: $437.1[\mathrm{M}+\mathrm{H}]^{+}$. 
Figure S1. The ${ }^{1} \mathrm{H}$ NMR, ${ }^{13} \mathrm{C}$ NMR, HRMS spectra and HPLC chromatogram of compound $7 \mathbf{a}$.
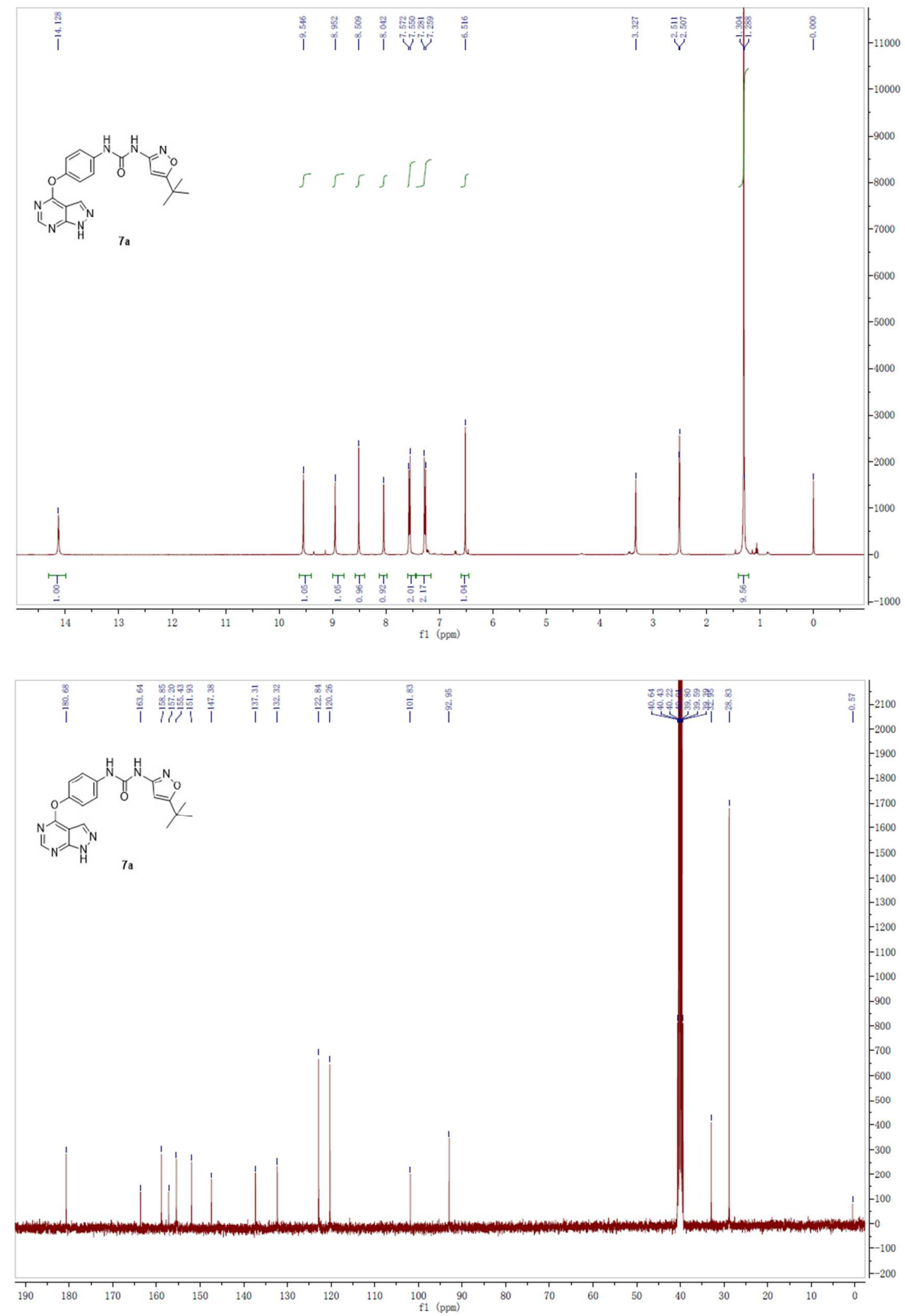

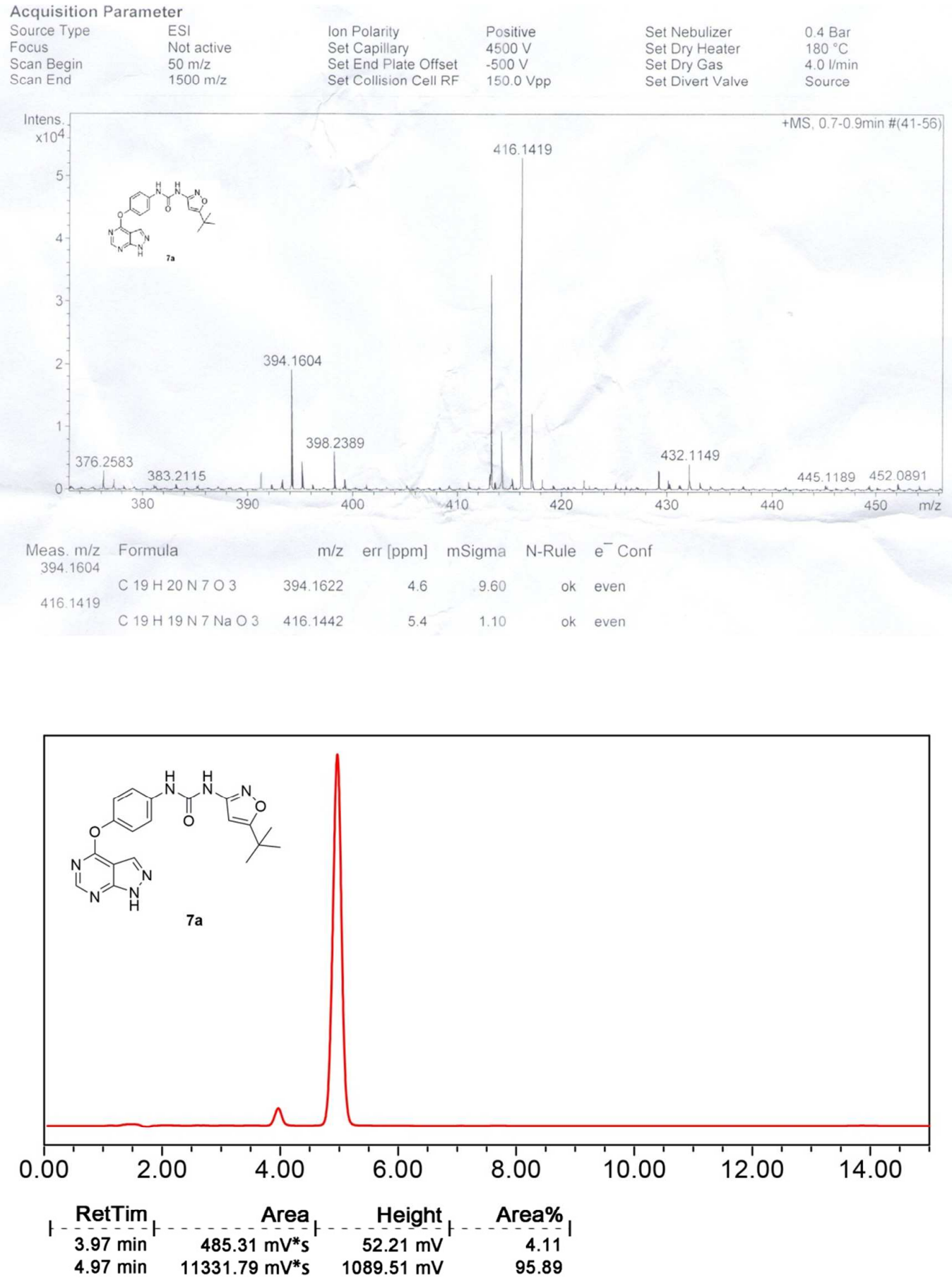
Figure S2. The ${ }^{1} \mathrm{H}$ NMR, ${ }^{13} \mathrm{C}$ NMR, HRMS spectra and HPLC chromatogram of compound $7 \mathbf{b}$.

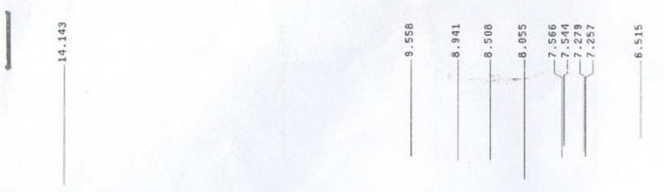

$7 b$

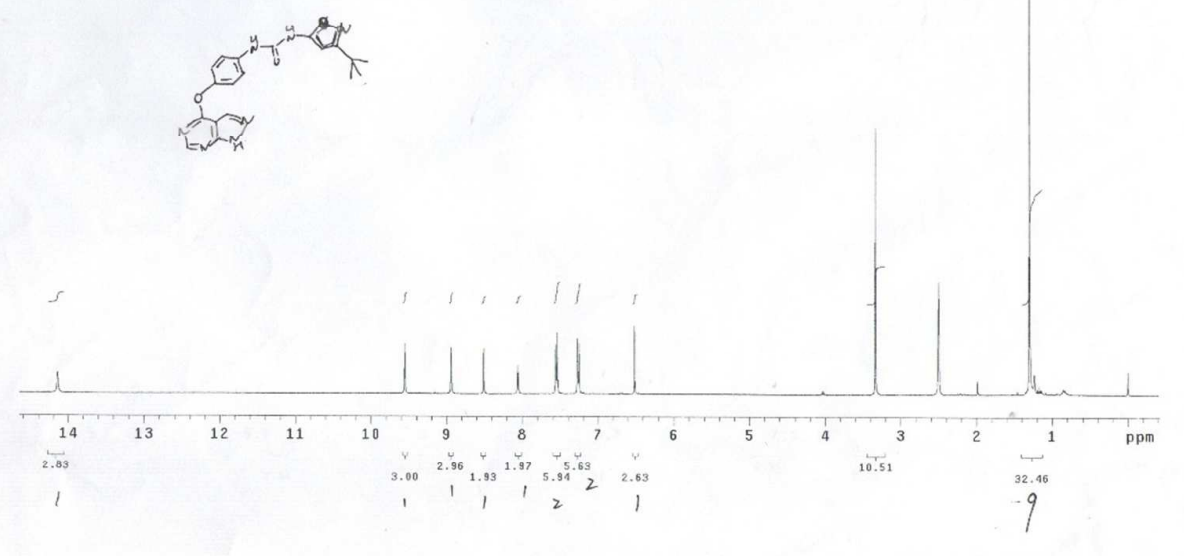

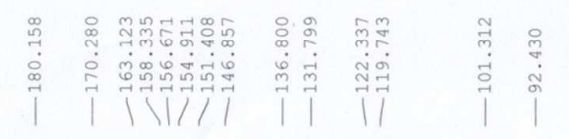
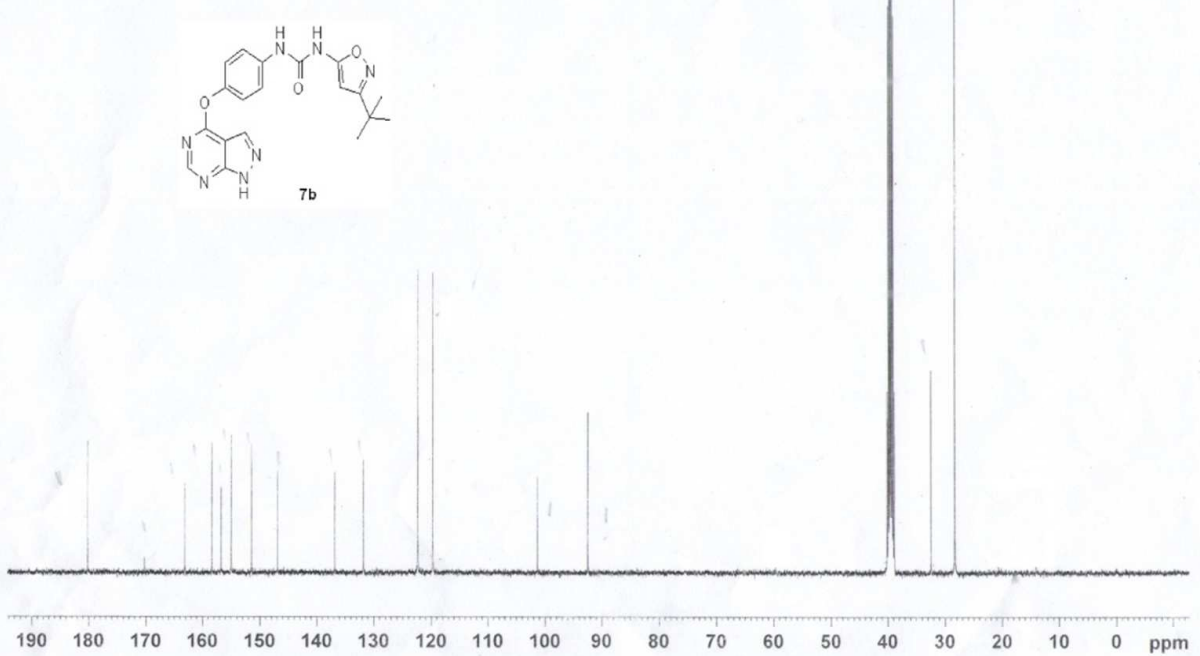

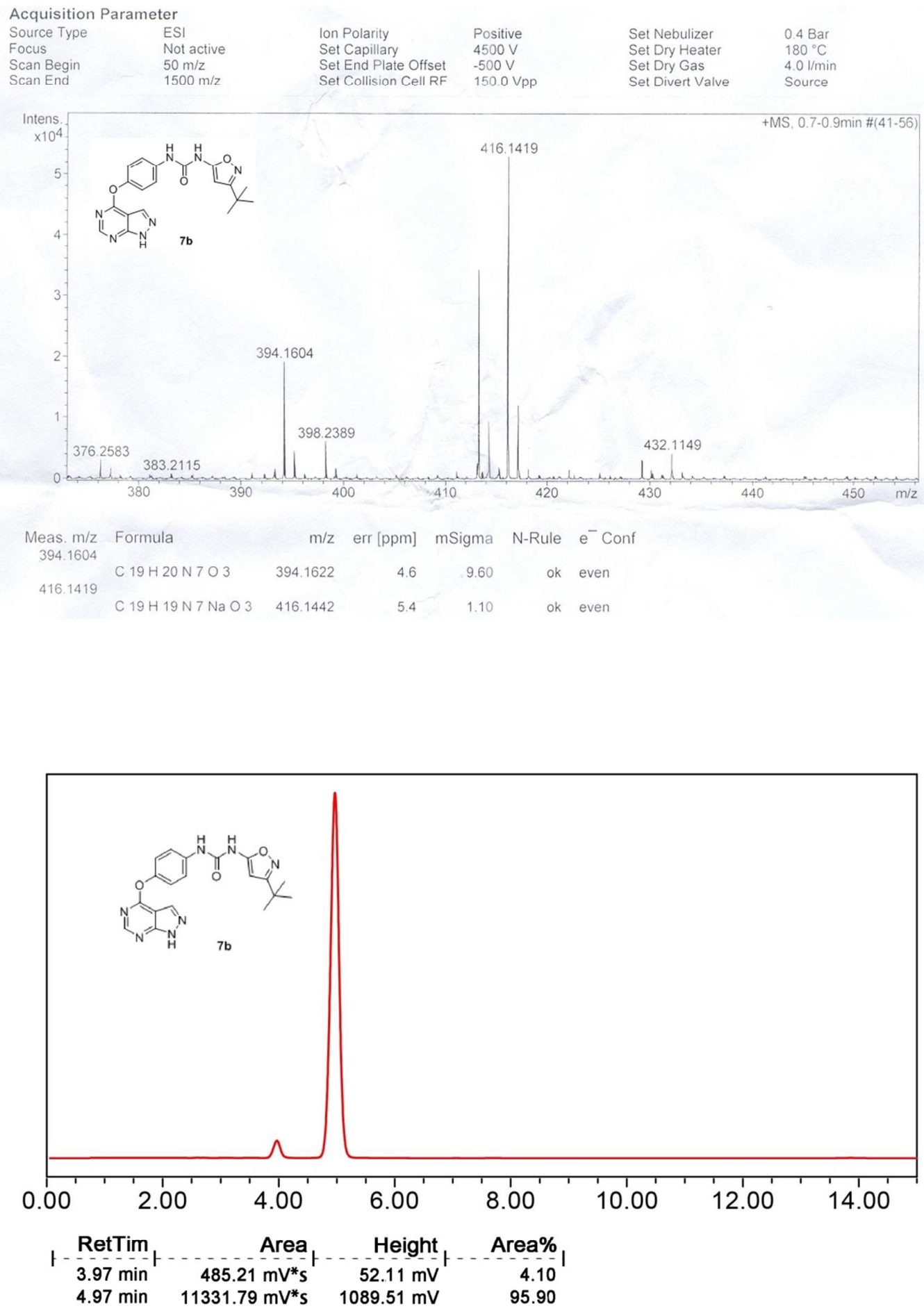
Figure S3. The ${ }^{1} \mathrm{H}$ NMR and ${ }^{13} \mathrm{C}$ NMR spectra of compound $7 \mathbf{c}$.
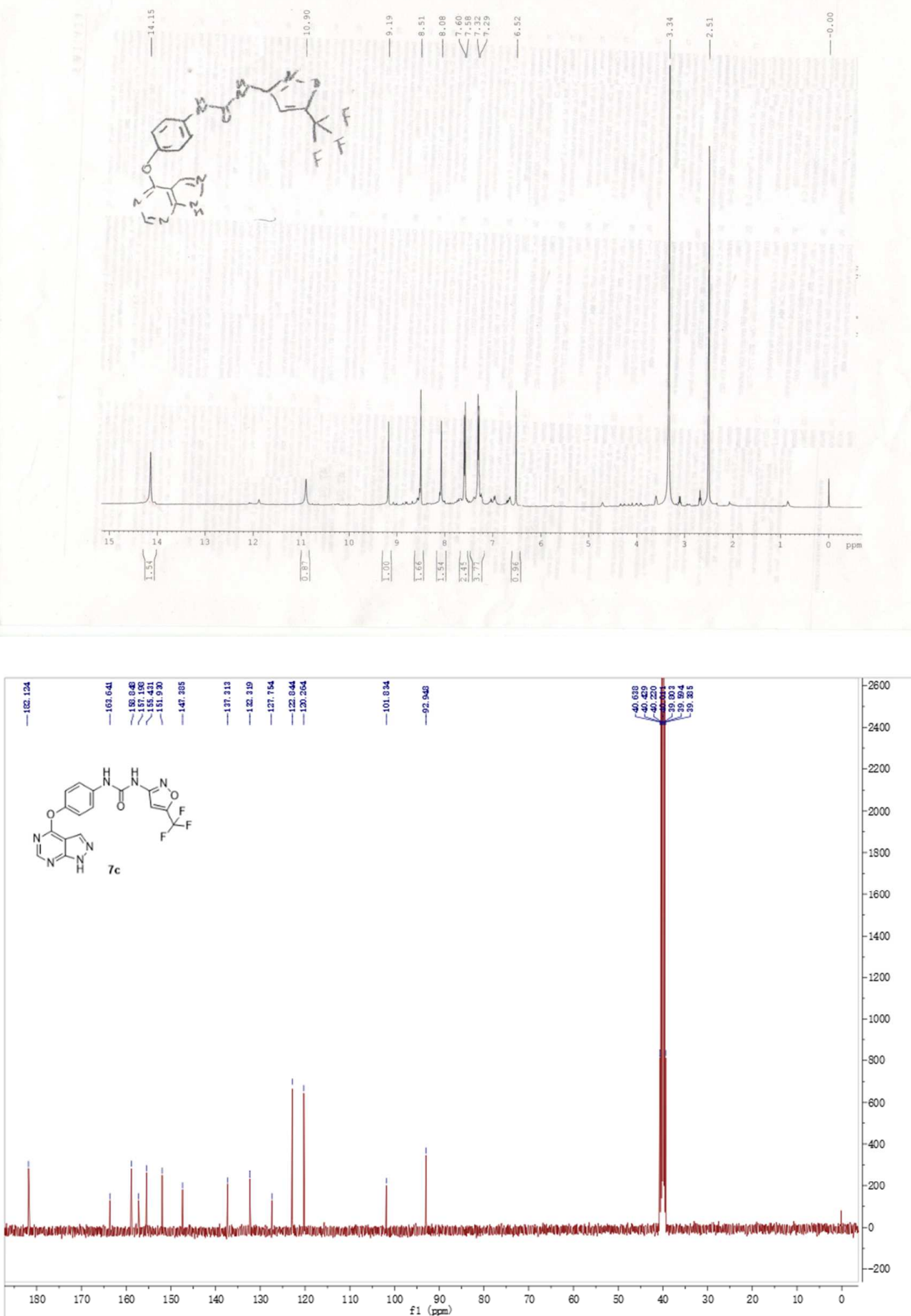
Figure S4. The ${ }^{1} \mathrm{H}$ NMR spectrum and HPLC chromatogram of compound 9a.
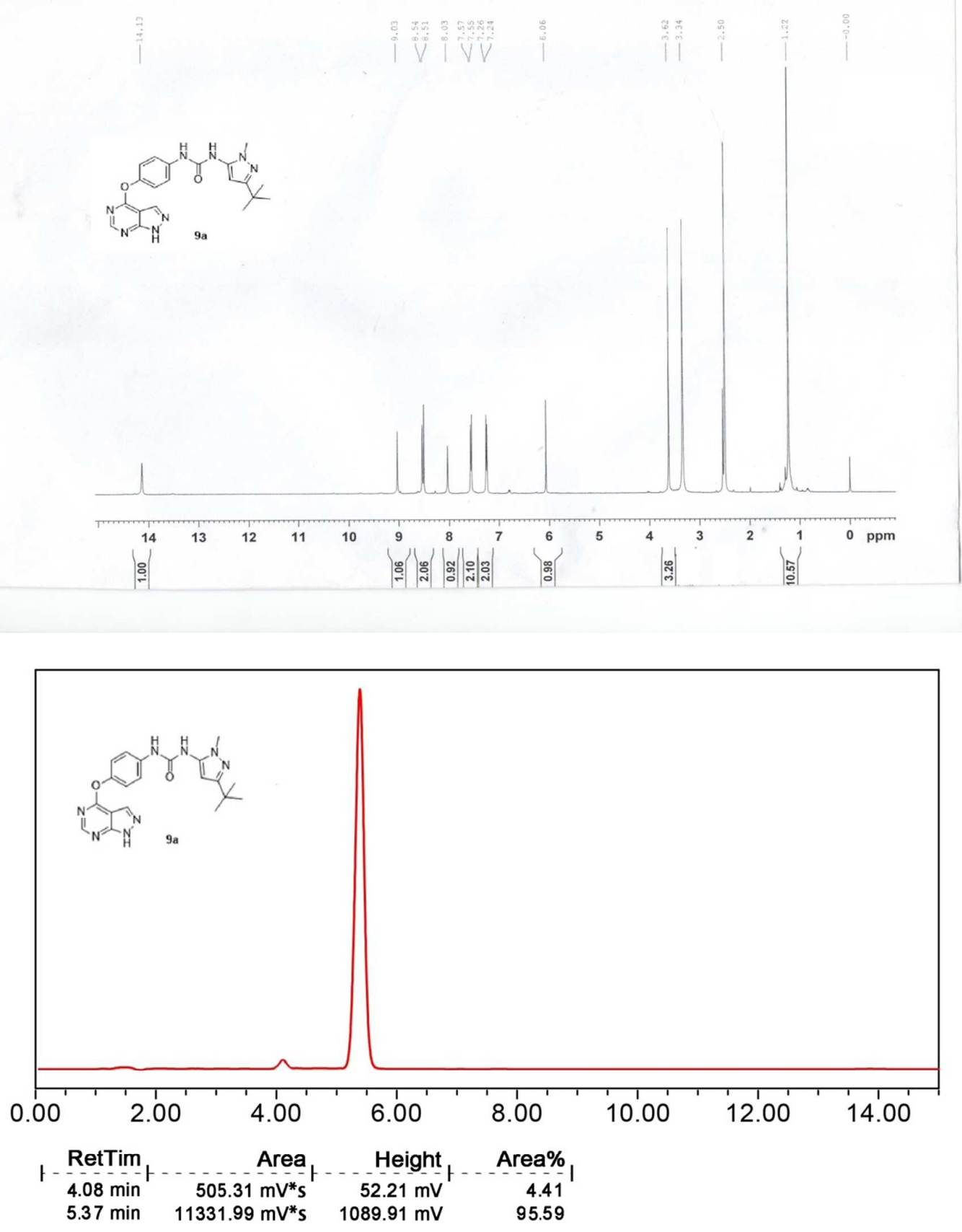
Figure S5. The ${ }^{1} \mathrm{H}$ NMR, ${ }^{13} \mathrm{C}$ NMR, HRMS spectra and HPLC chromatogram of compound $\mathbf{9 b}$.
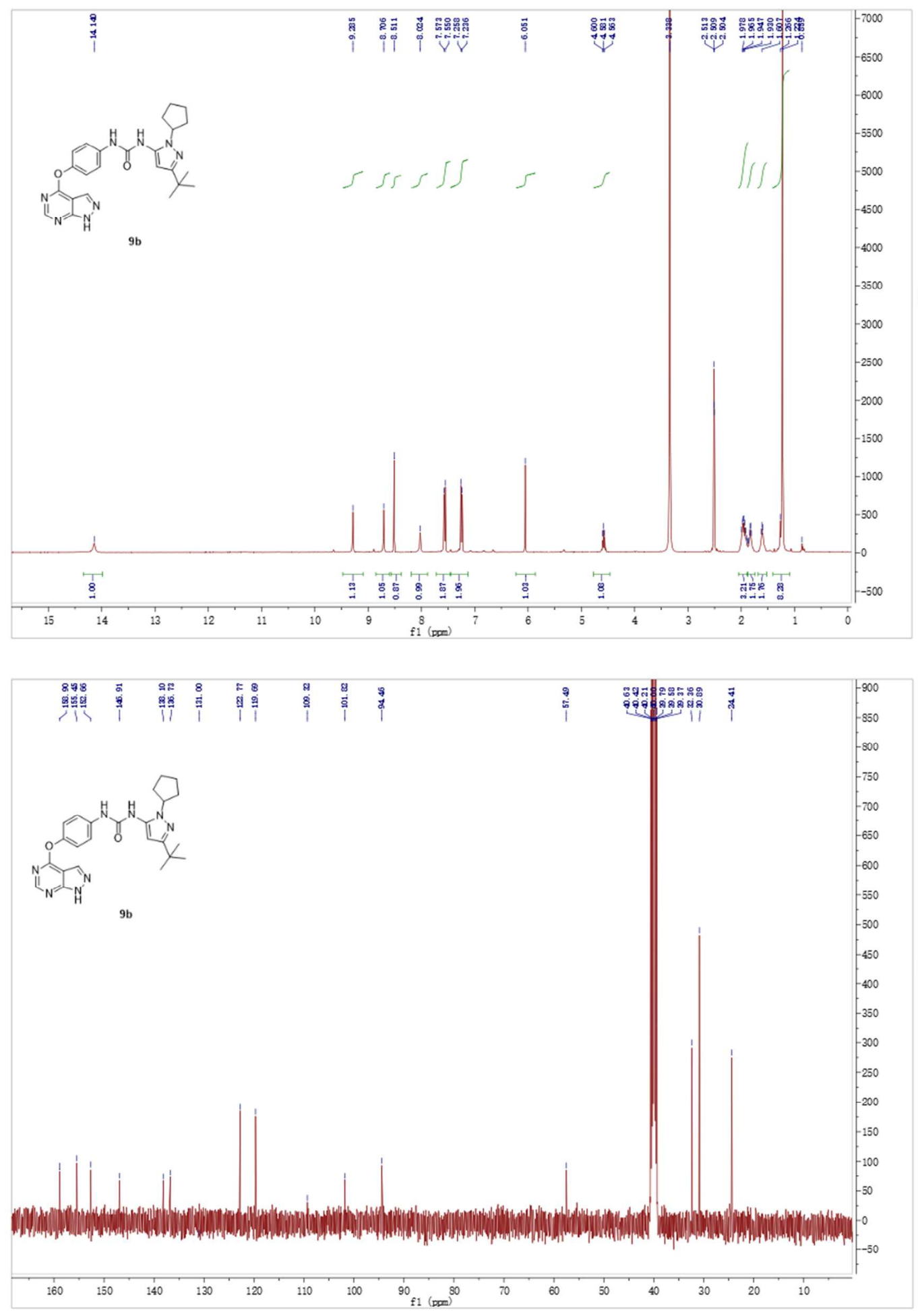

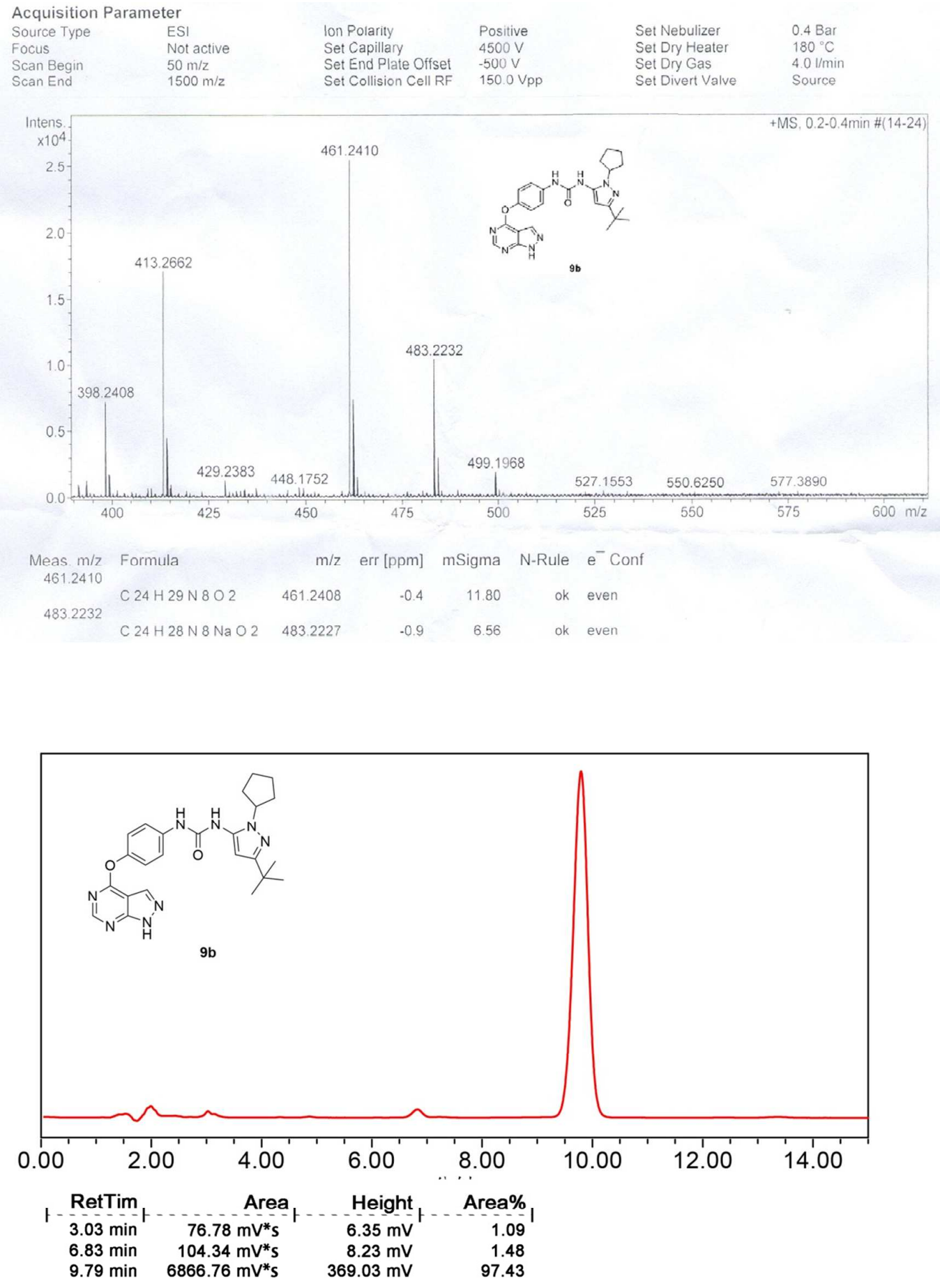
Figure S6. The ${ }^{1} \mathrm{H}$ NMR, ${ }^{13} \mathrm{C}$ NMR spectra and HPLC chromatogram of compound 9c.
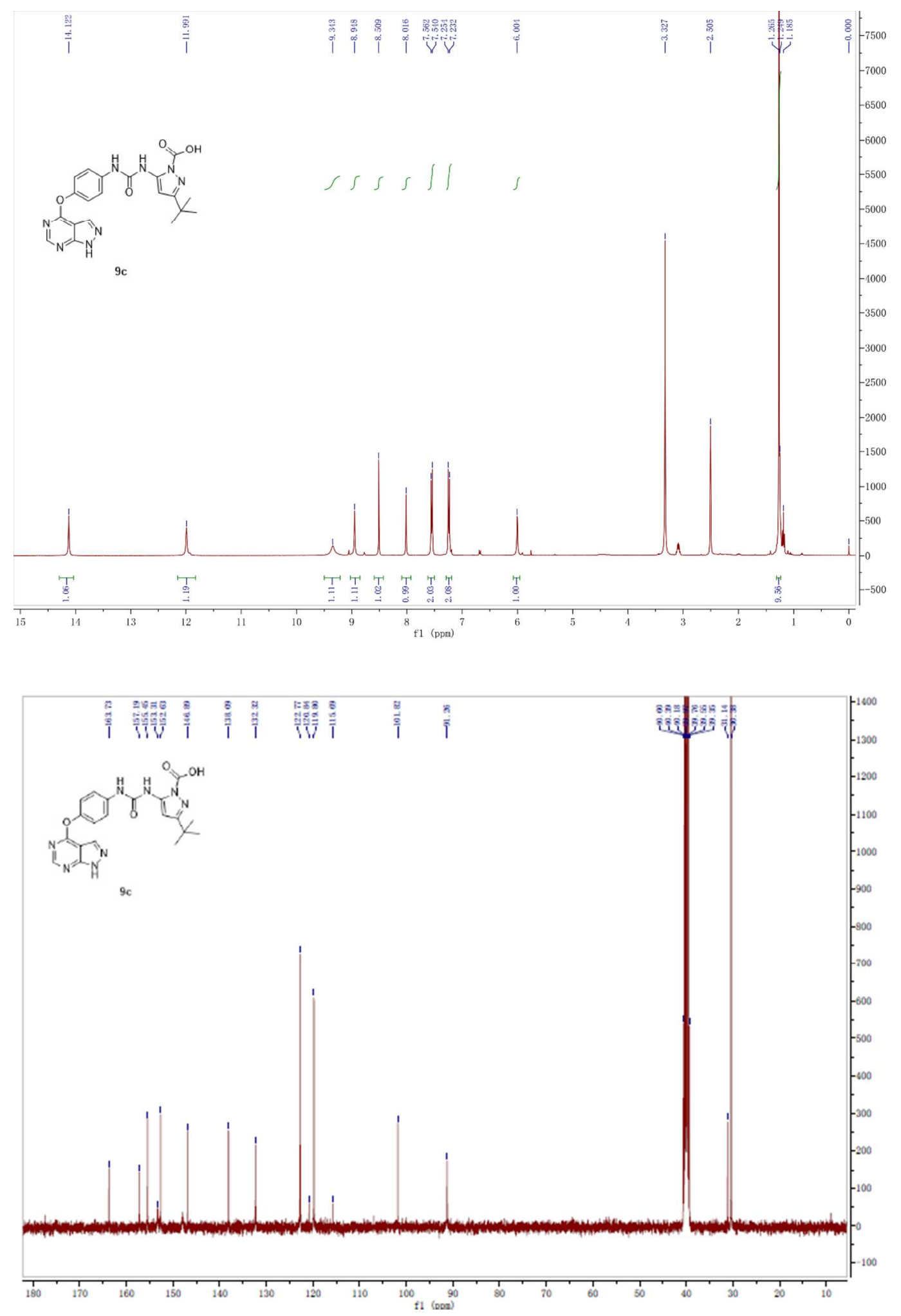


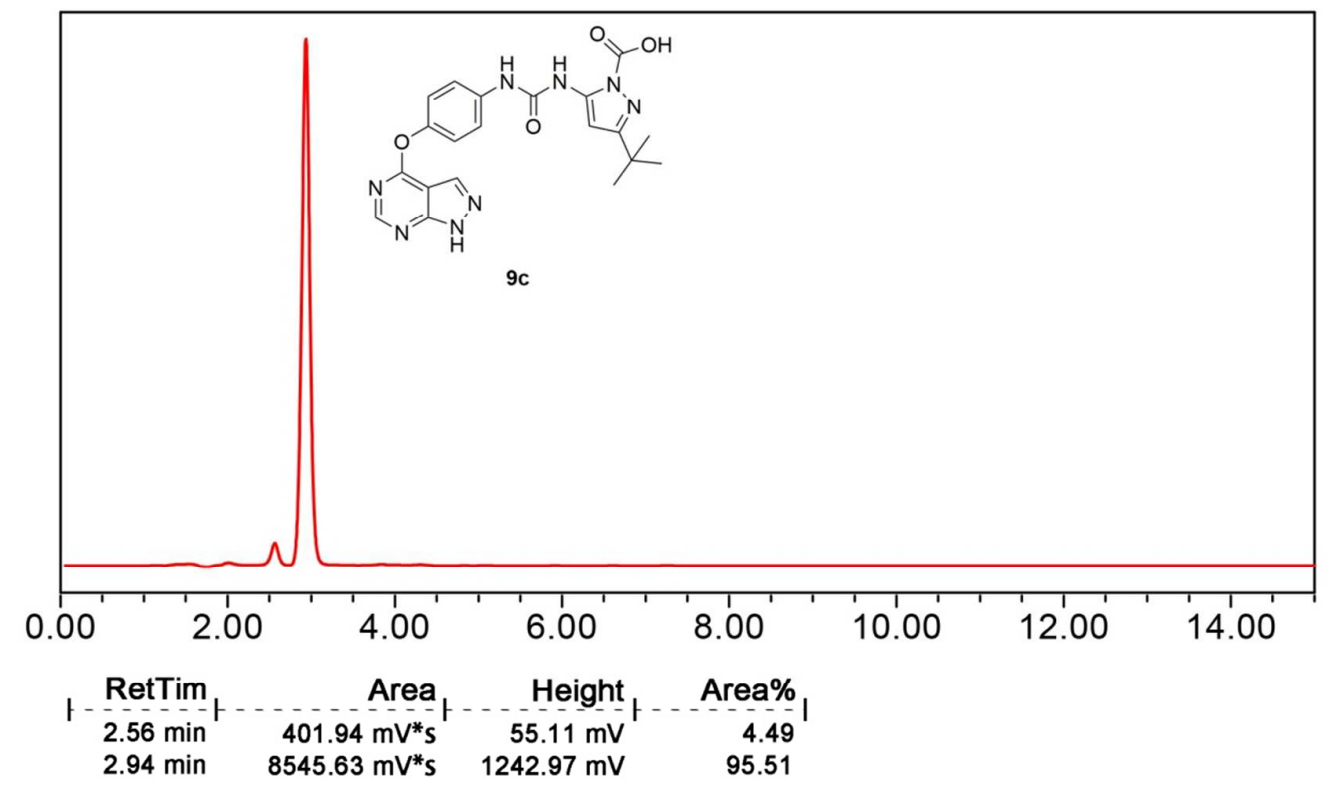


Figure S7. The ${ }^{1} \mathrm{H}$ NMR spectrum and HPLC chromatogram of compound 9d.
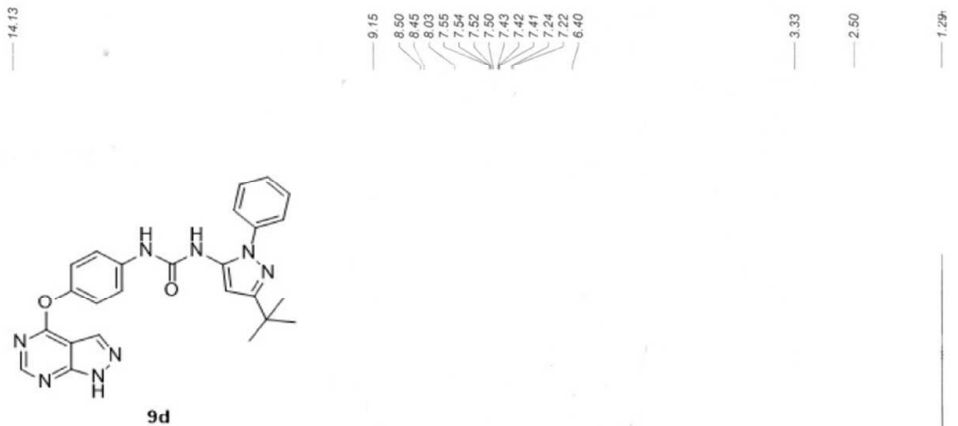

$9 d$
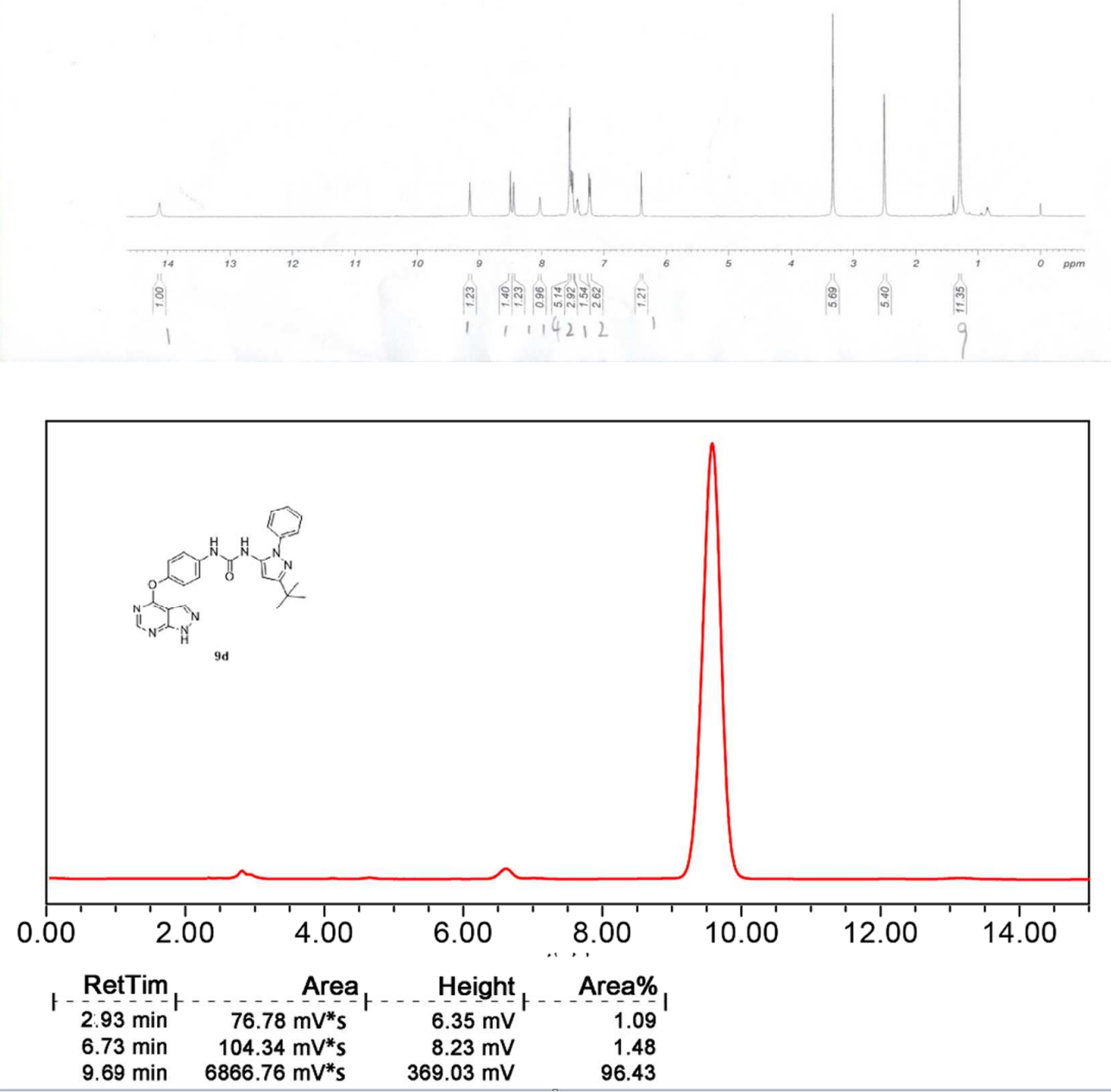
Figure S8. The ${ }^{1} \mathrm{H}$ NMR spectrum and HPLC chromatogram of compound 9e.
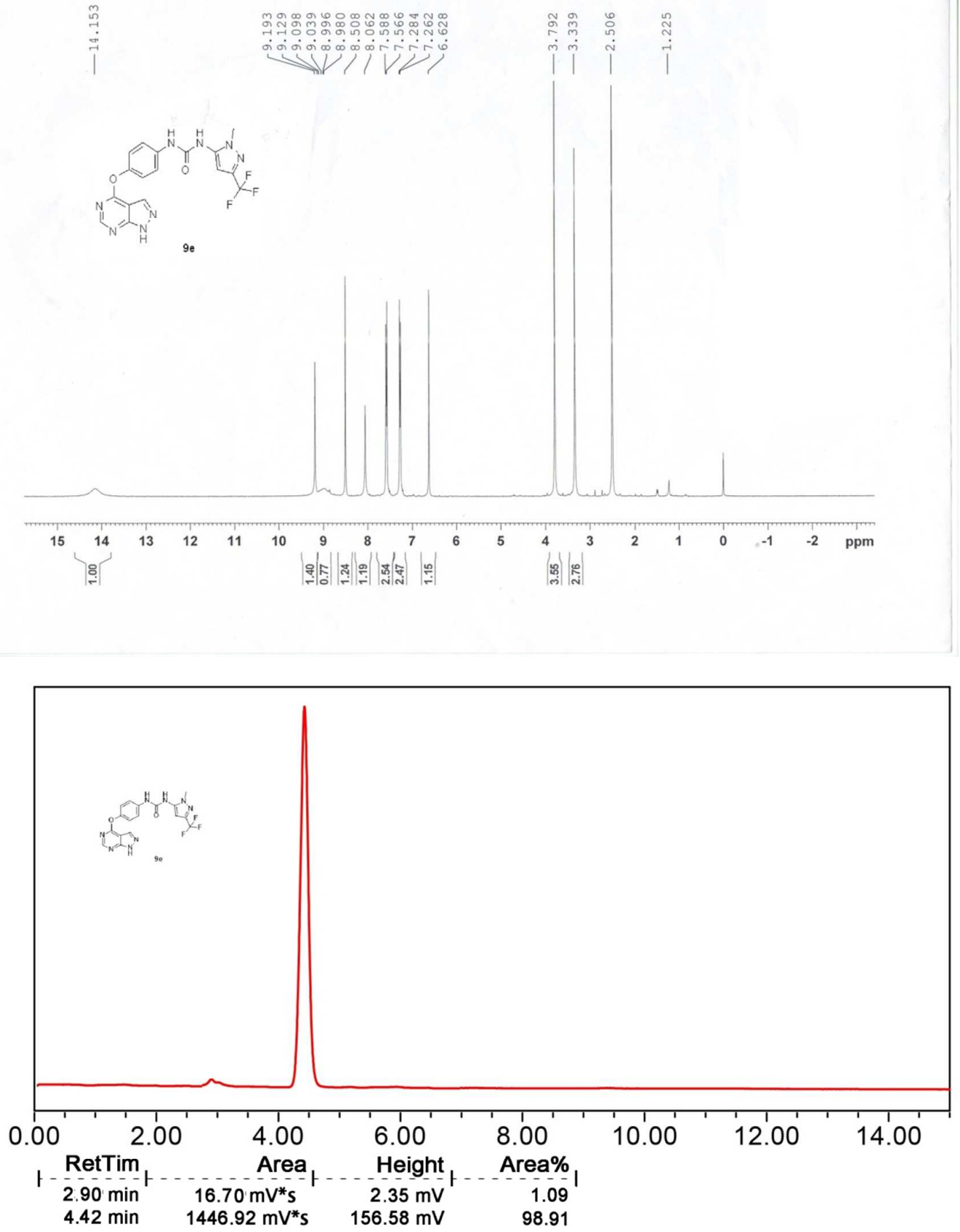
Figure S9. The ${ }^{1} \mathrm{H}$ NMR spectrum and HPLC chromatogram of compound 9 f.
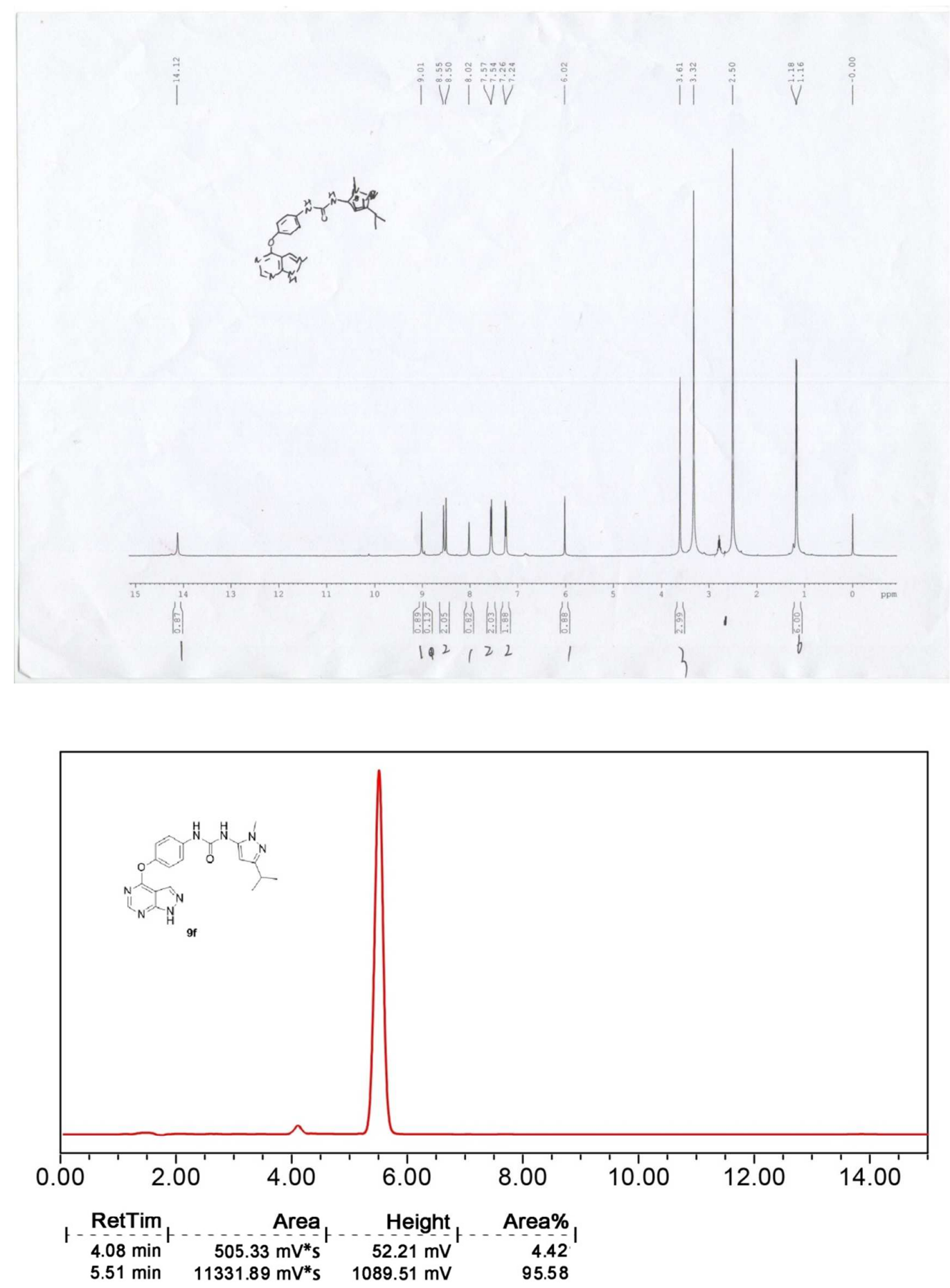
Figure S10. The ${ }^{1} \mathrm{H}$ NMR, ${ }^{13} \mathrm{C}$ NMR, HRMS spectra and HPLC chromatogram of compound 12a.
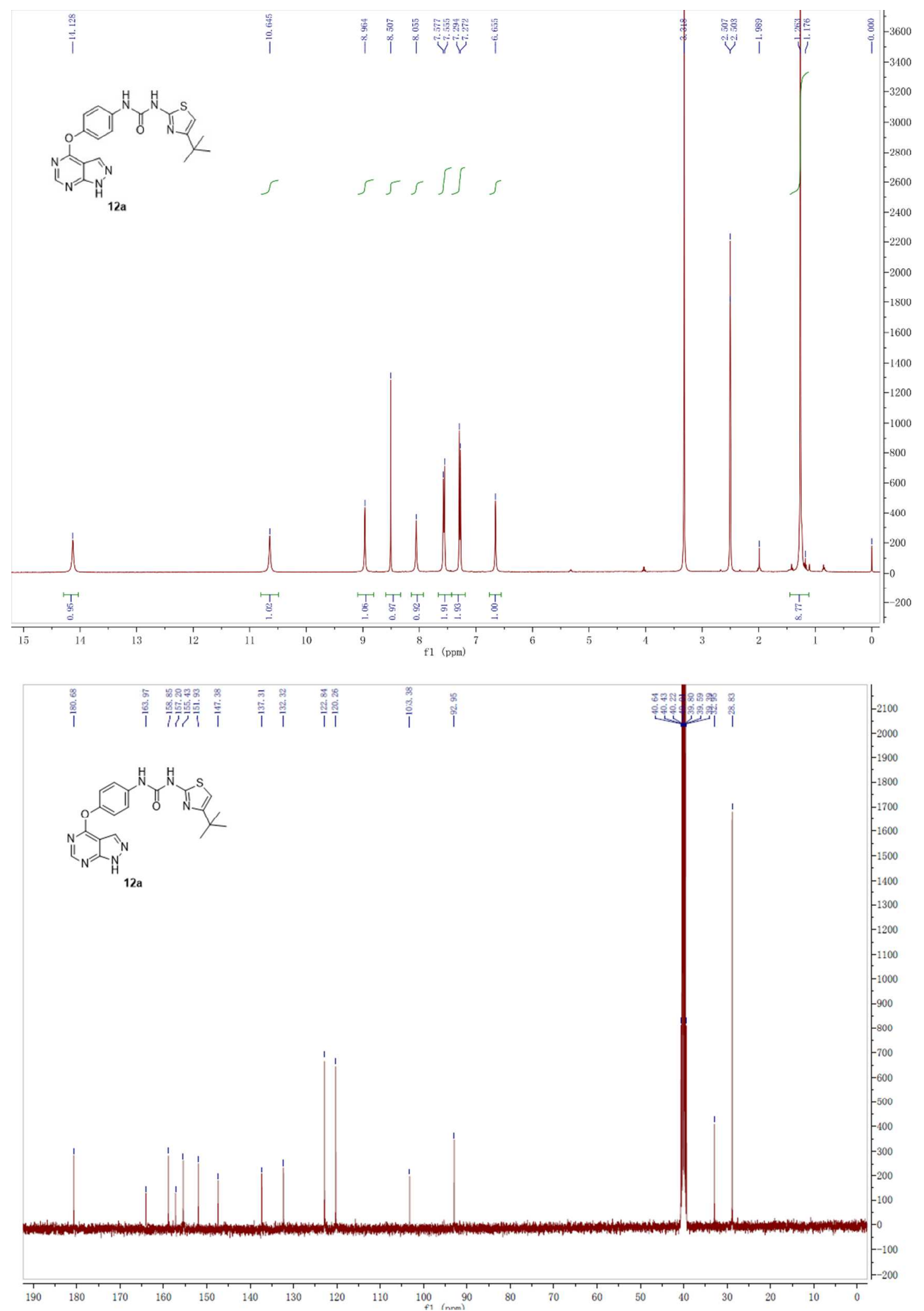

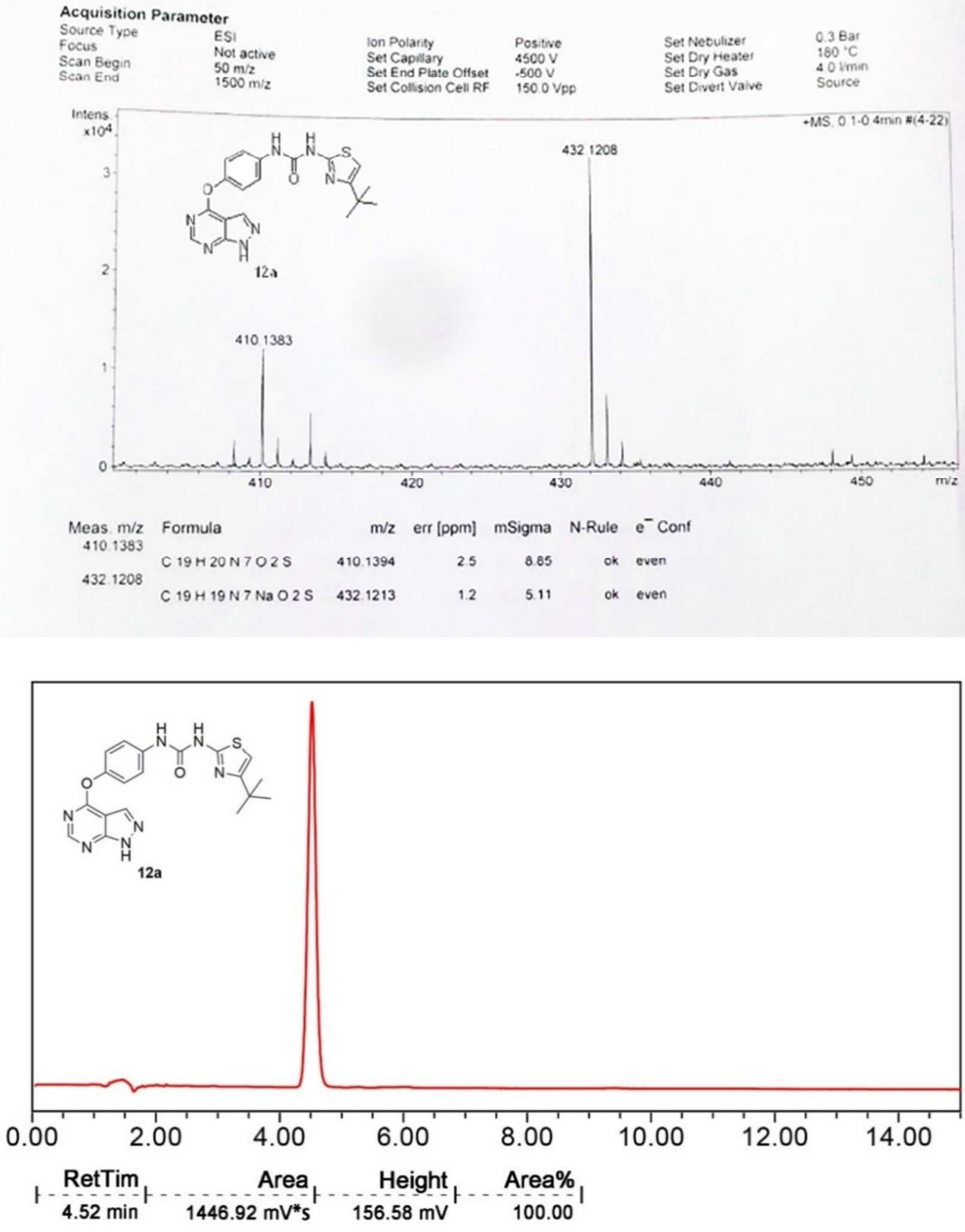
Figure S11. The ${ }^{1} \mathrm{H}$ NMR, HRMS spectra and HPLC chromatogram of compound $12 b$.

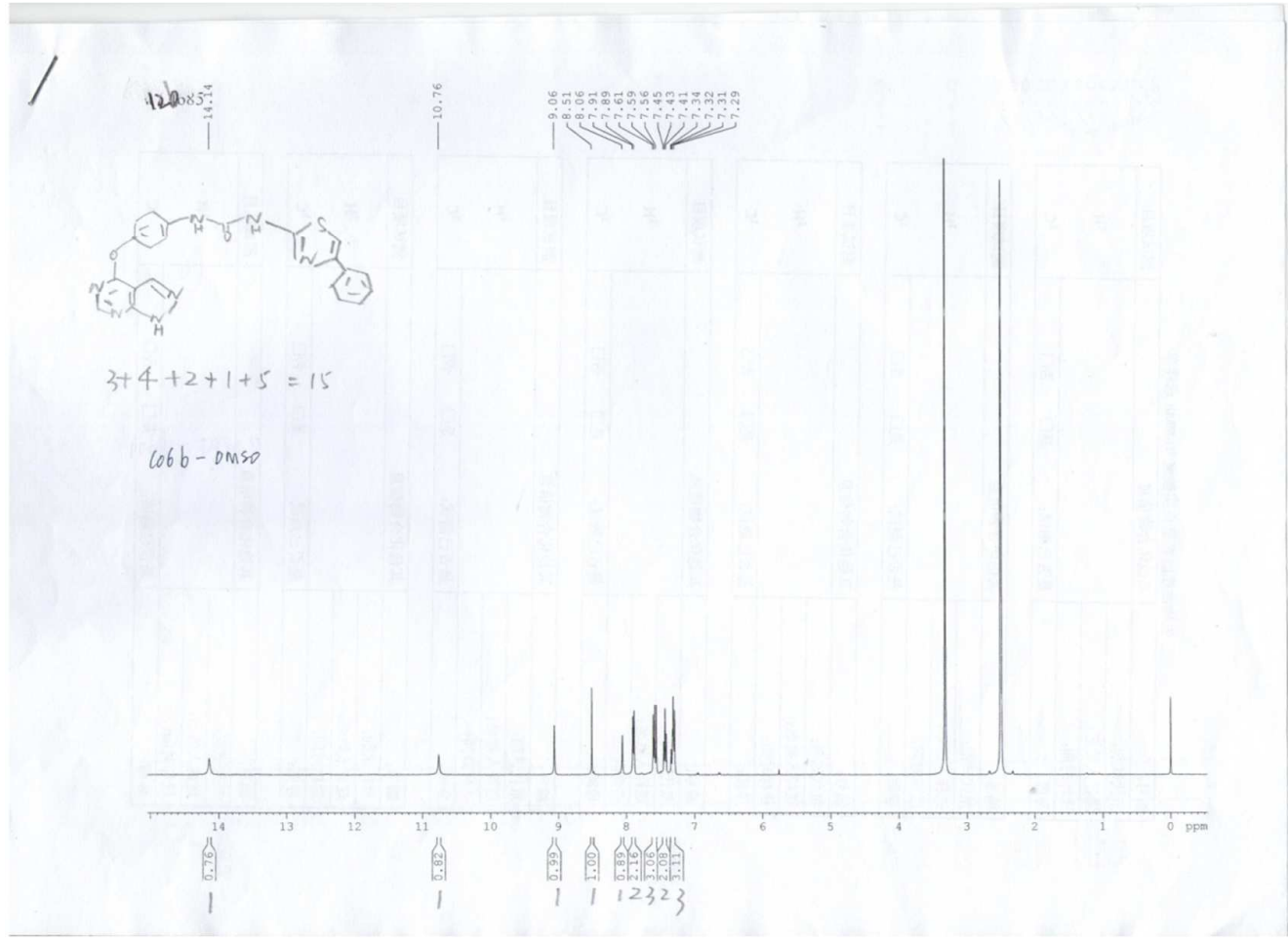

\begin{tabular}{llllll}
\multicolumn{2}{l}{ Acquisition Parameter } & & & \\
Source Type & ESI & Ion Polarity & Positive & Set Nebulizer & $0.4 \mathrm{Bar}$ \\
Focus & Not active & Set Capillary & $4500 \mathrm{~V}$ & Set Dry Heater & $180^{\circ} \mathrm{C}$ \\
Scan Begin & $50 \mathrm{~m} / 7$ & Set End Plate Offset & $.500 \mathrm{~V}$ & Set Dry Gas & $4.01 / \mathrm{min}$ \\
Scan End & $1500 \mathrm{~m} / \mathrm{z}$ & Set Collision Cell RF & $150.0 \mathrm{Vpp}$ & Set Divert Valve & Source
\end{tabular}

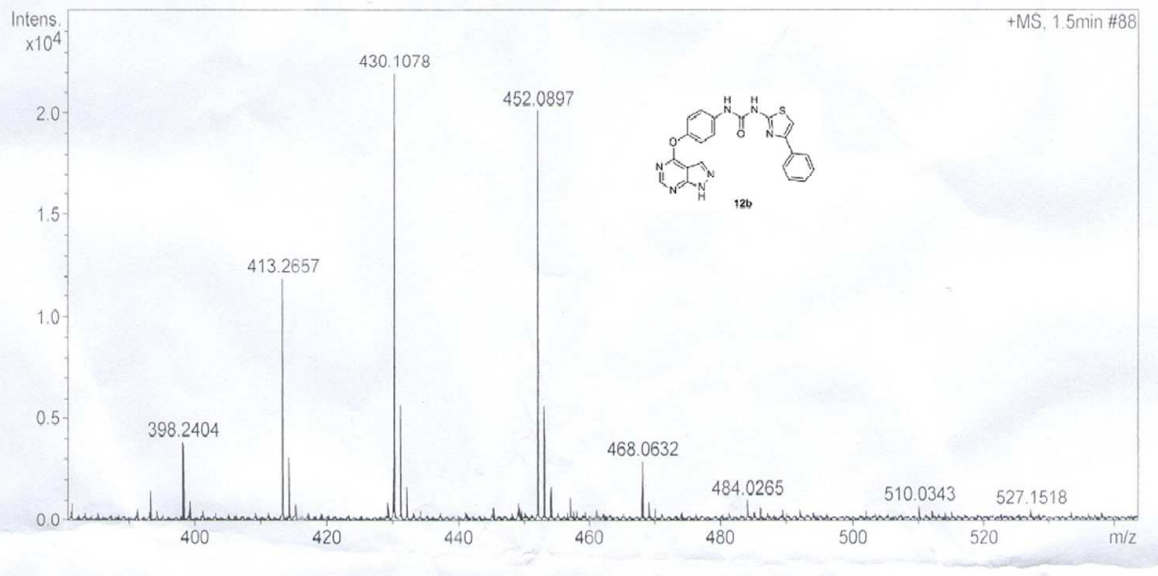
430.107

430.1078

C $21 \mathrm{H} 16 \mathrm{~N} 7 \mathrm{O} 2 \mathrm{~S} \quad 430.1081$

m/z err $[\mathrm{ppm}] \quad m$ Sigma $N$-Rule $e^{-}$Conf

452.0897 


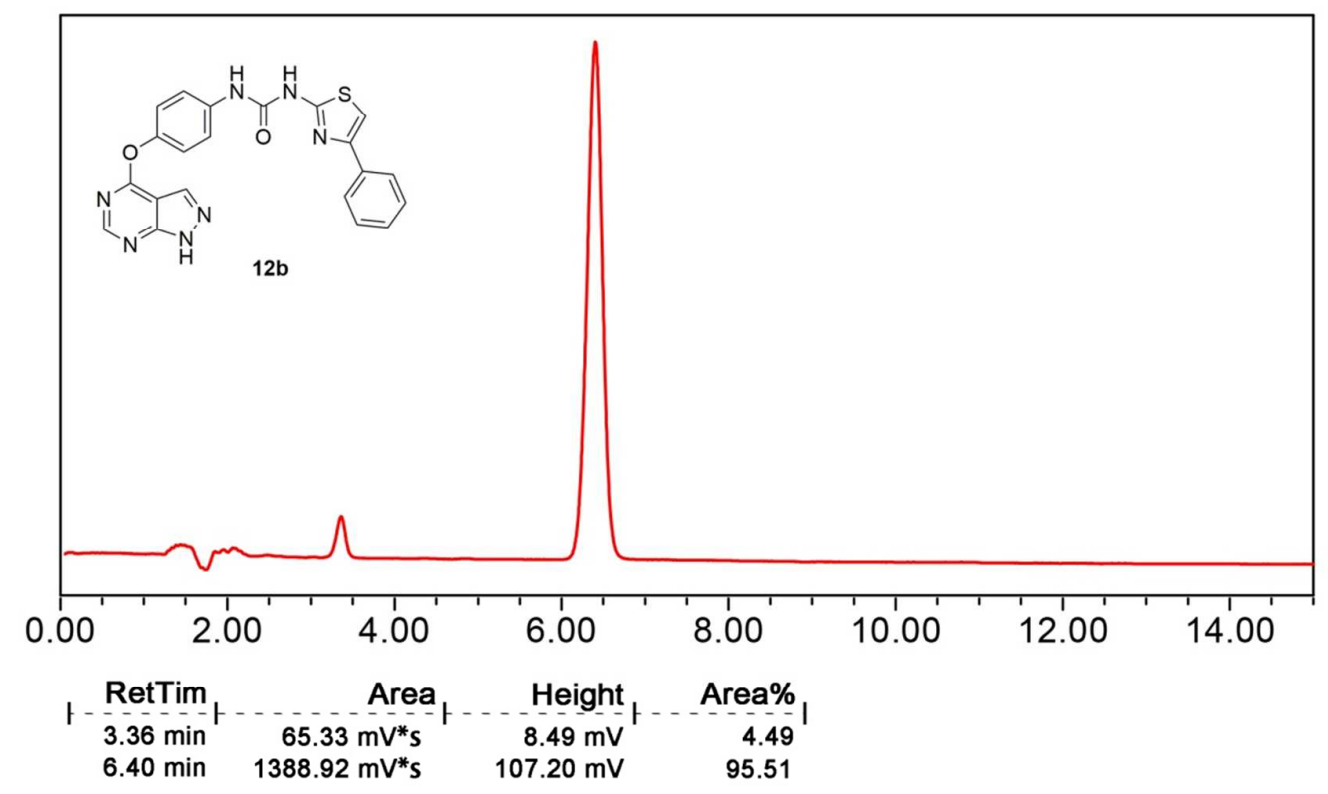


Figure S12. The ${ }^{1} \mathrm{H}$ NMR spectrum and HPLC chromatogram of compound 14.
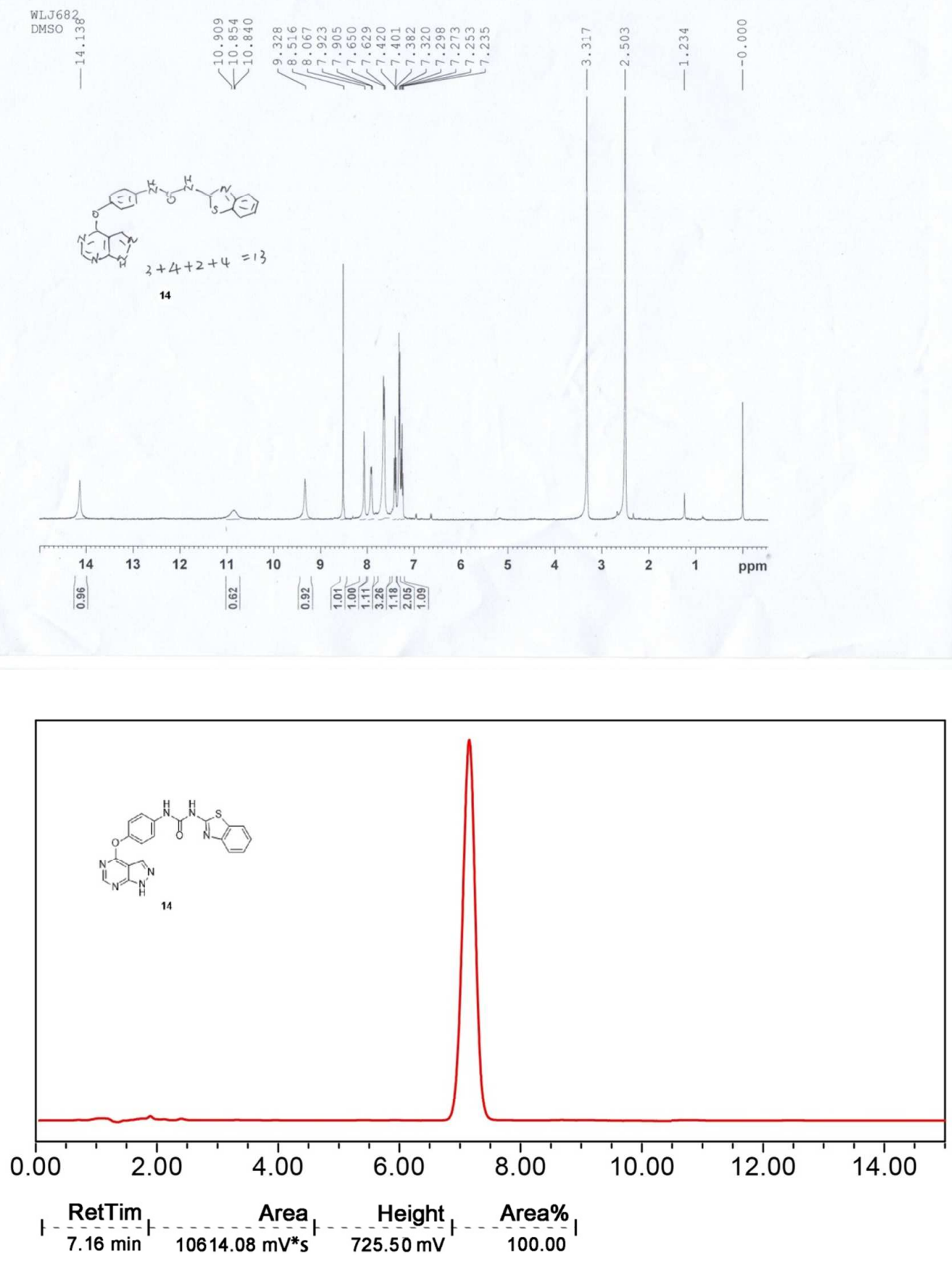
Figure S13. The ${ }^{1} \mathrm{H}$ NMR, ${ }^{13} \mathrm{C}$ NMR, HRMS spectra and HPLC chromatogram of compound 16a.
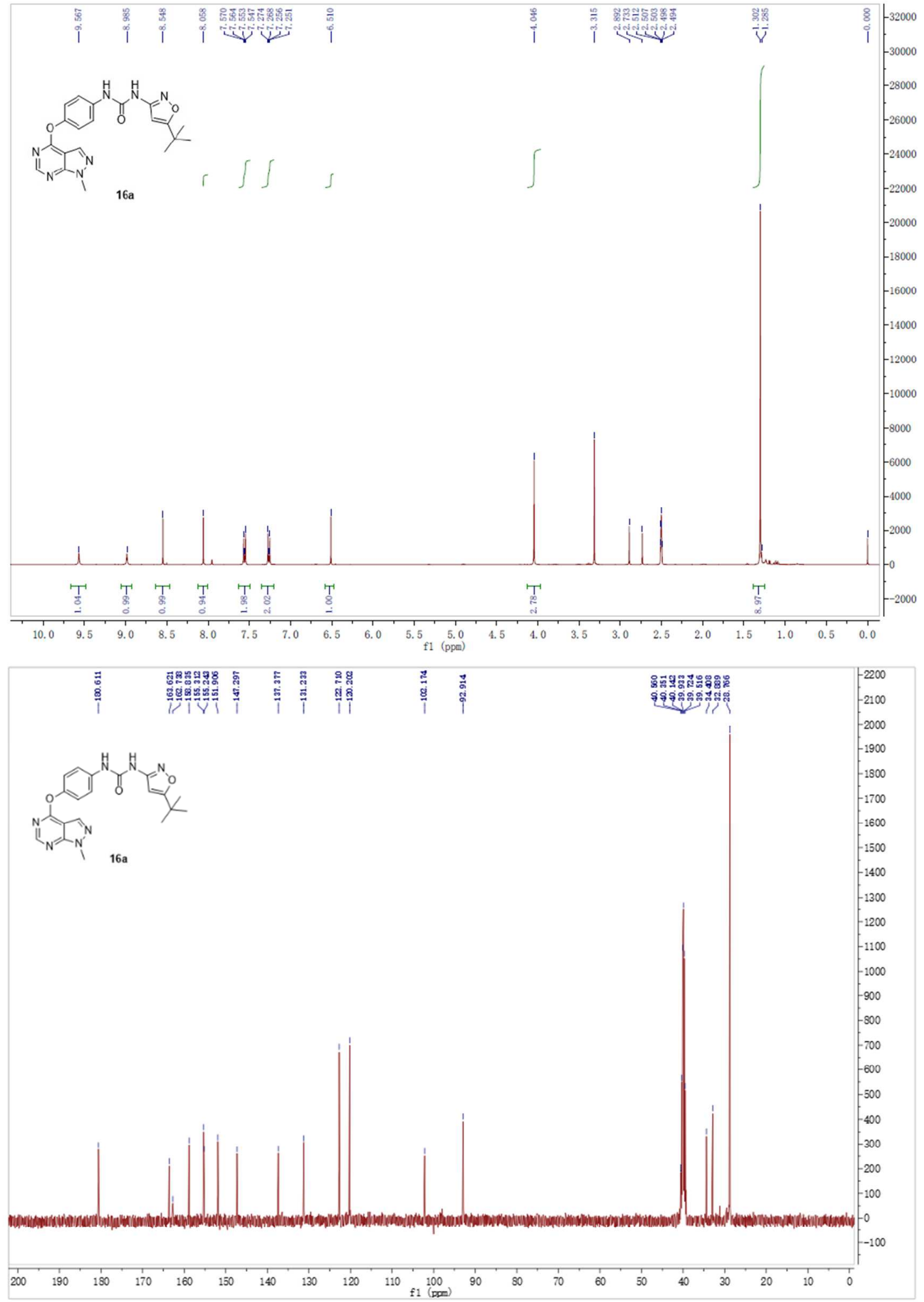


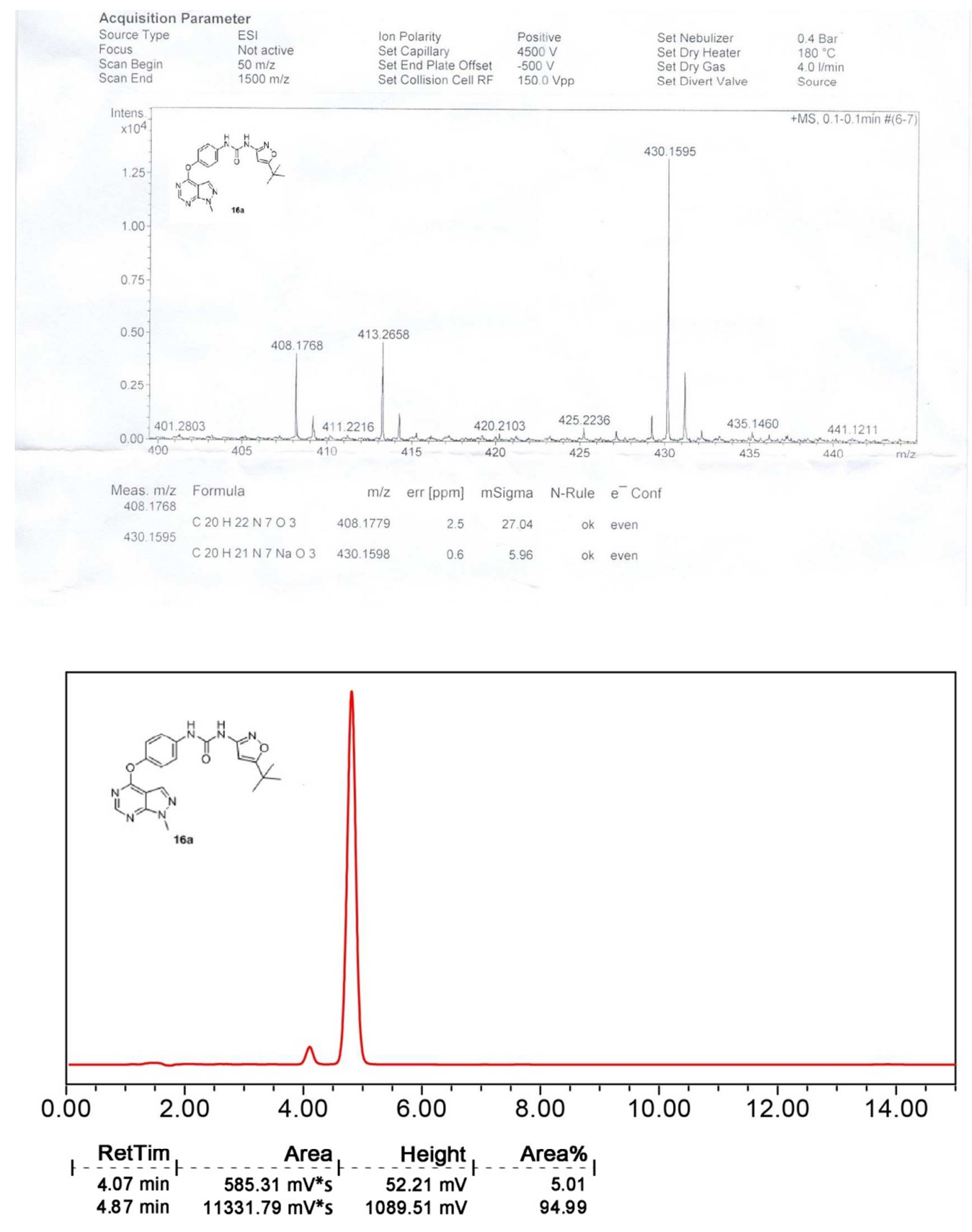


Figure S14. The ${ }^{1} \mathrm{H}$ NMR, ${ }^{13} \mathrm{C}$ NMR, HRMS spectra and HPLC chromatogram of compound 16b.
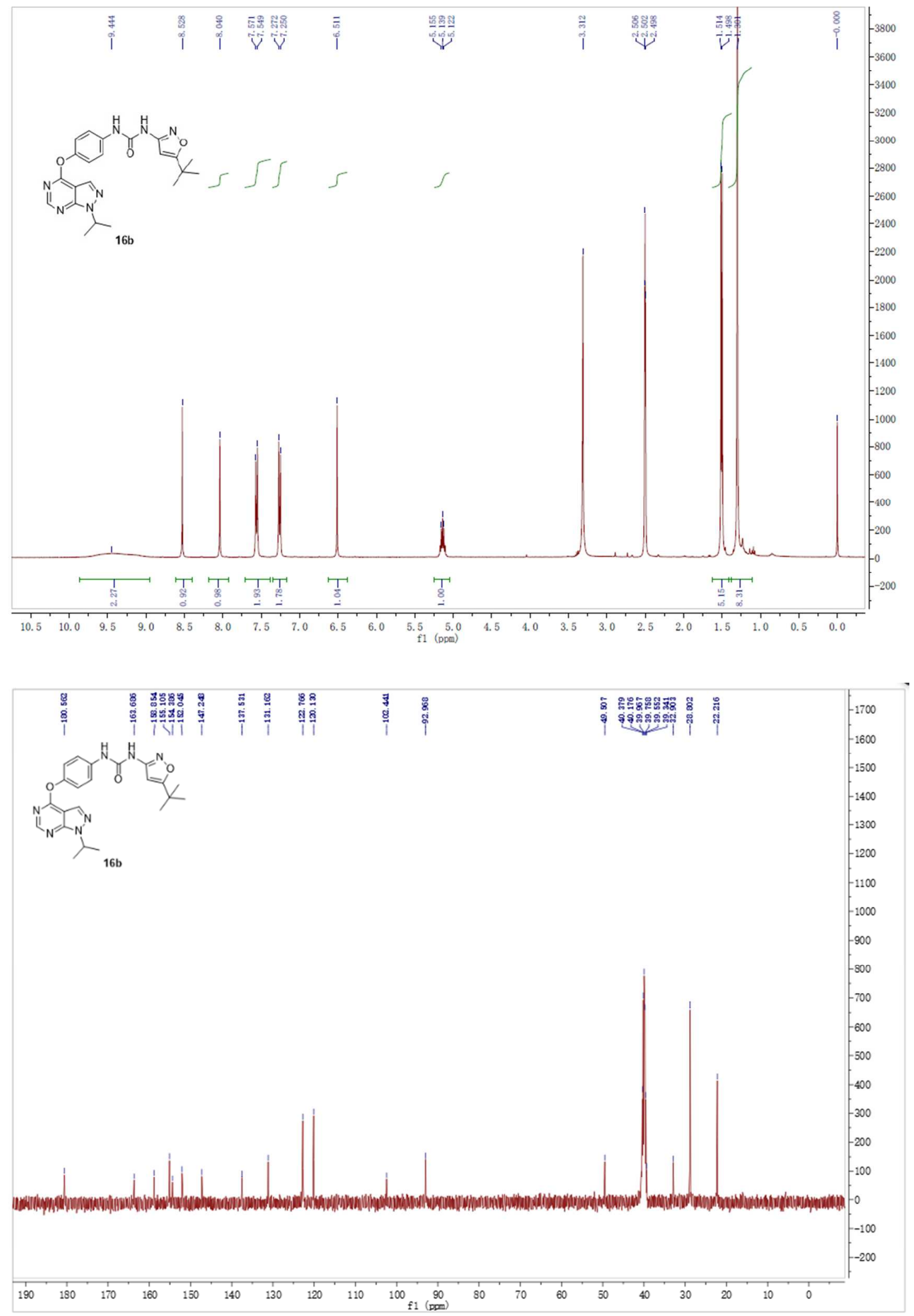

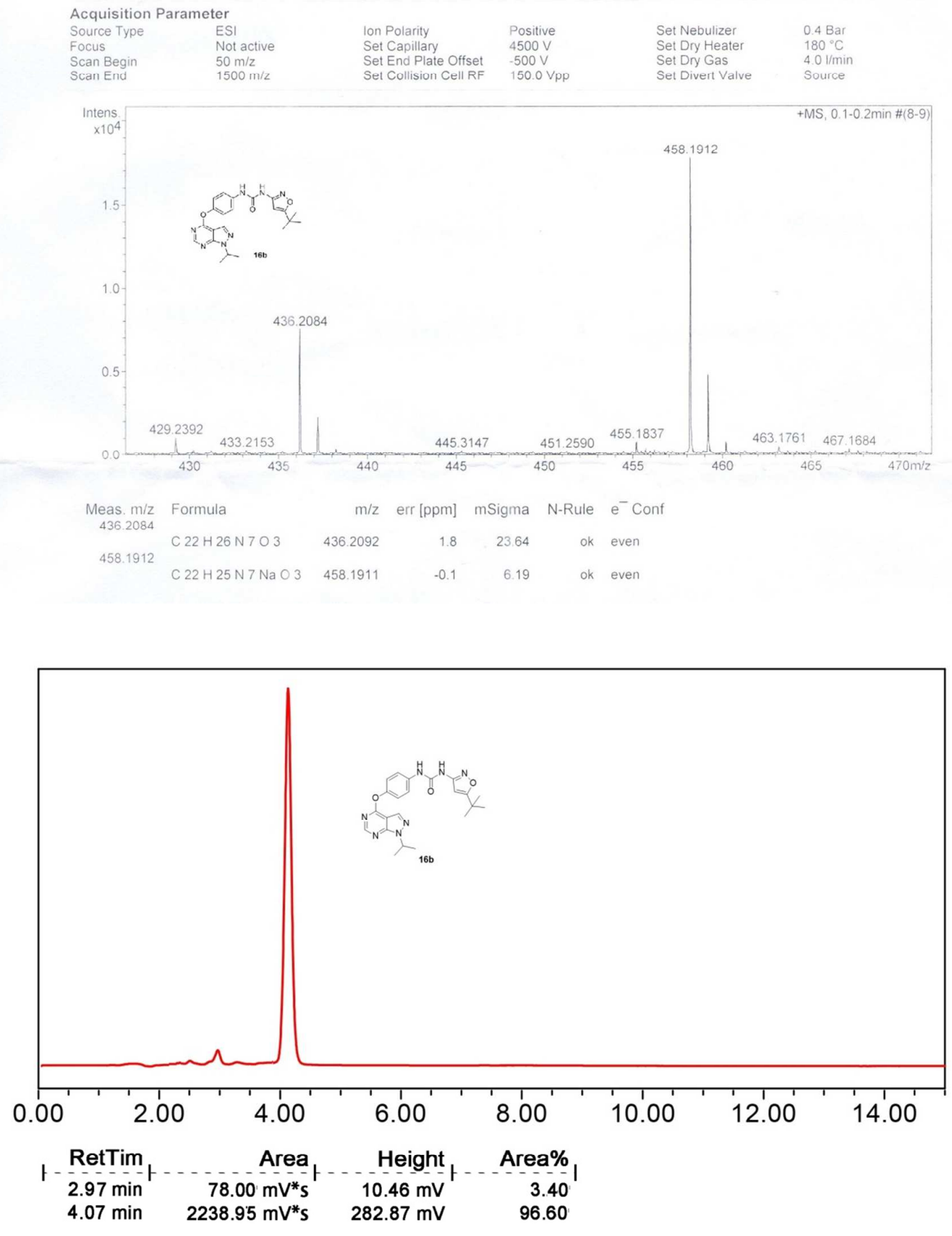
Figure S15. The ${ }^{1} \mathrm{H}$ NMR spectrum of compound $\mathbf{1 6 c}$.

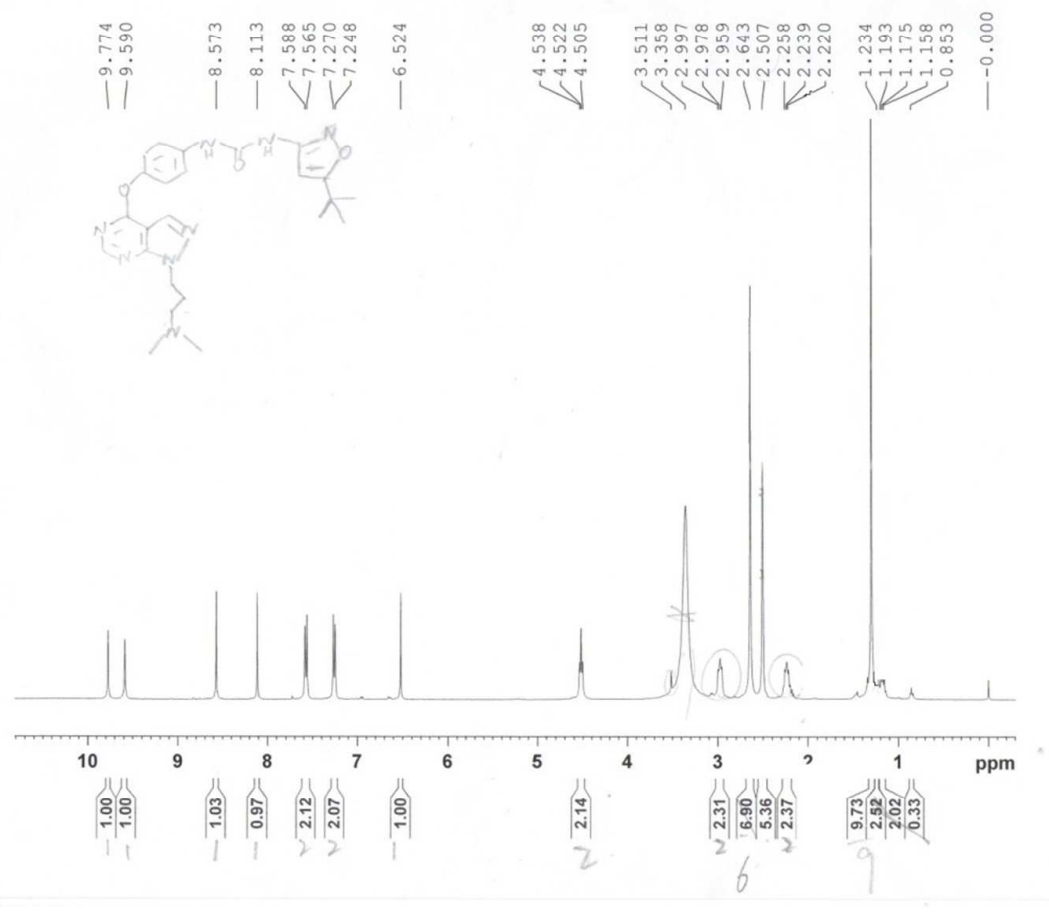


Figure S16. The ${ }^{1} \mathrm{H}$ NMR, ${ }^{13} \mathrm{C}$ NMR, HRMS spectra and HPLC chromatogram of compound 16d.
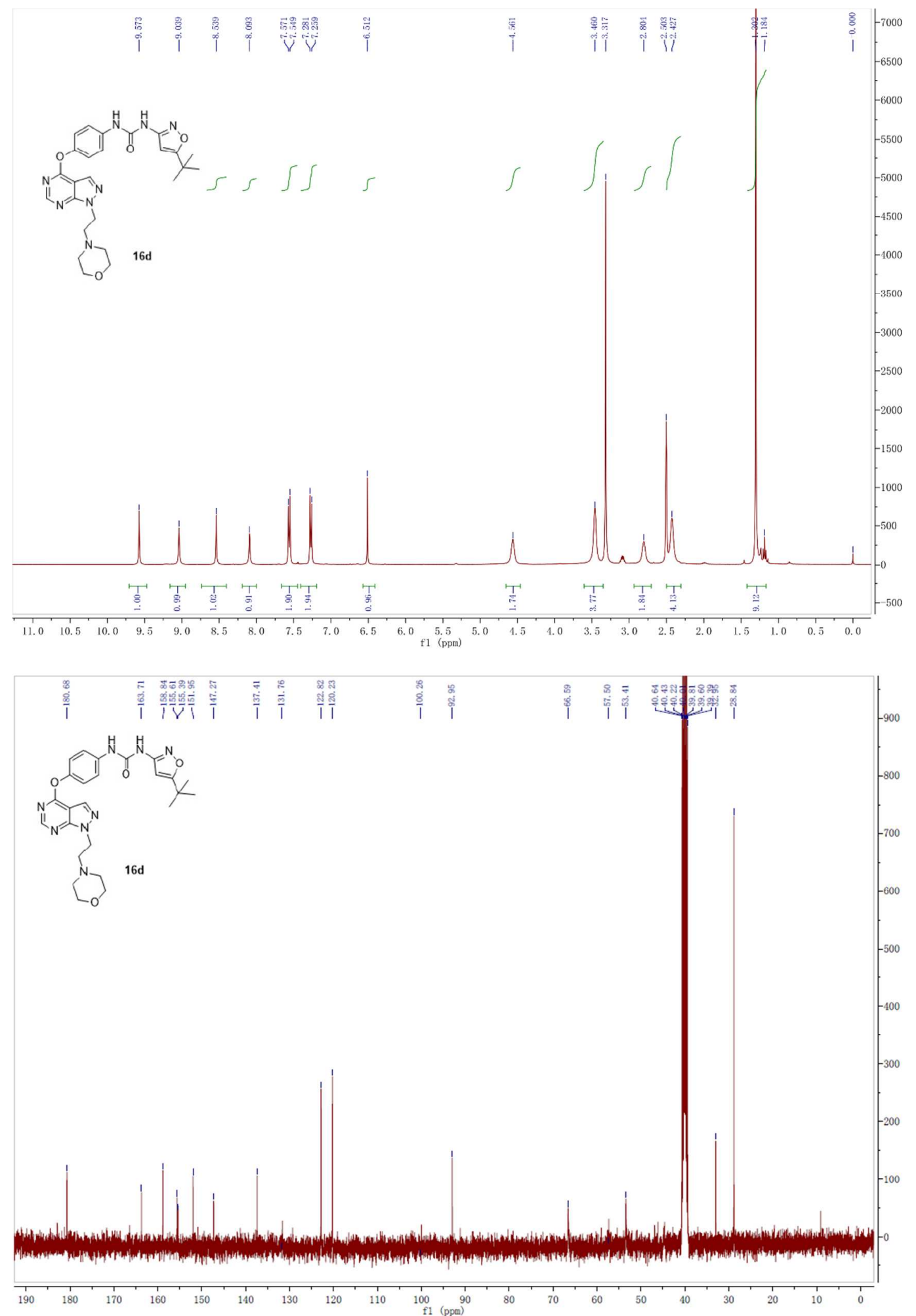

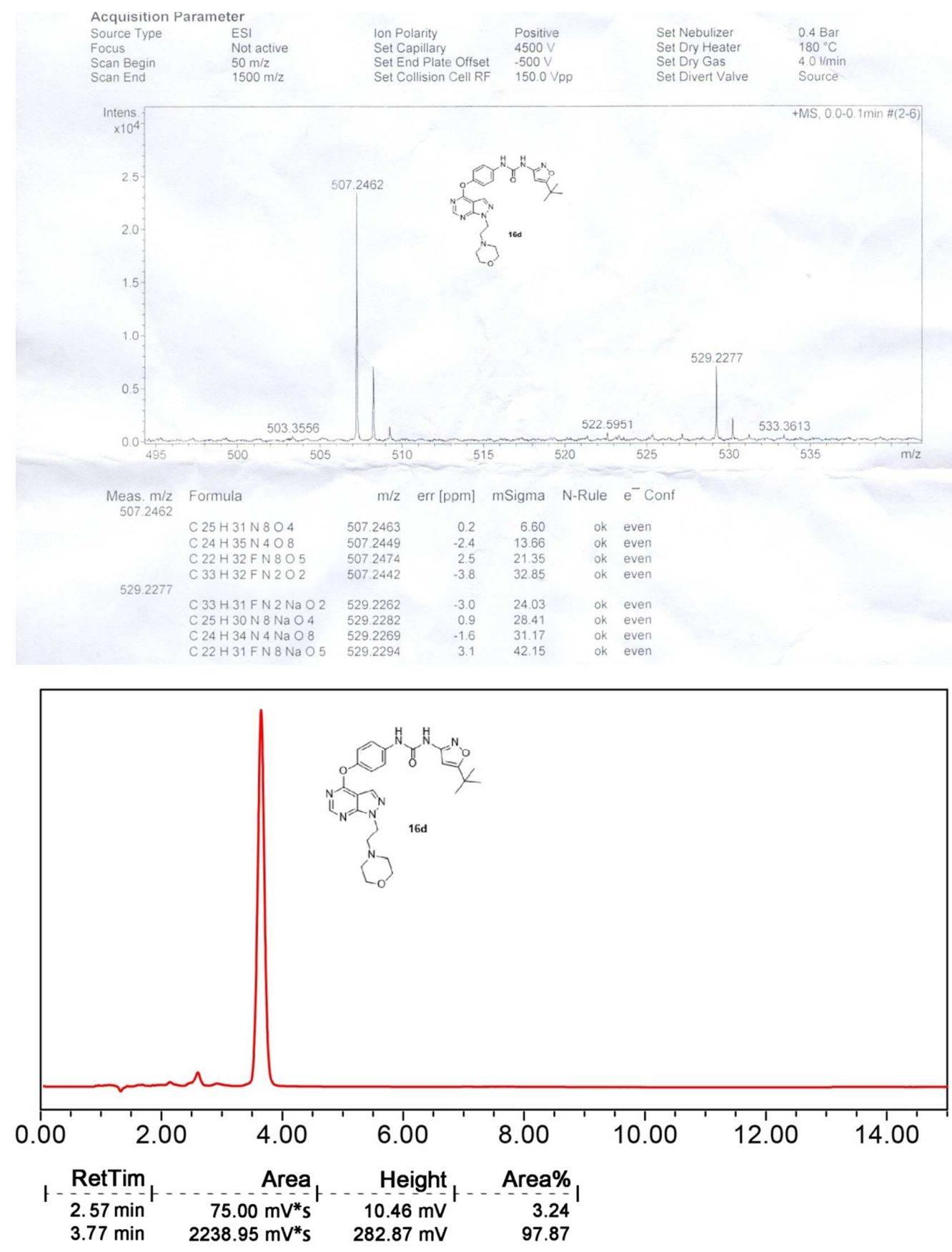
Figure S17. The ${ }^{1} \mathrm{H}$ NMR, ${ }^{13} \mathrm{C}$ NMR, HRMS spectra and HPLC chromatogram of compound 18a.
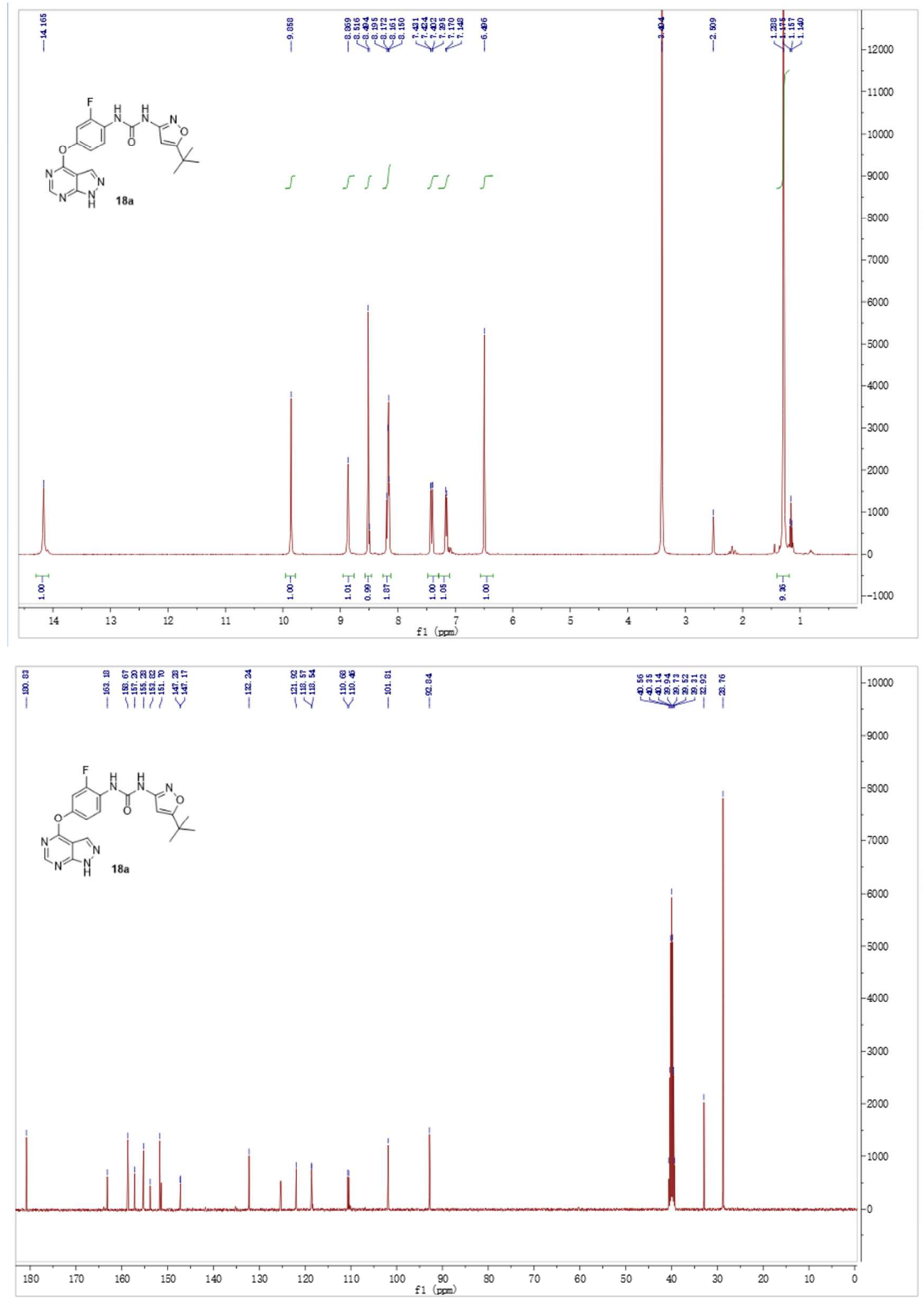
Acquisition Parameter

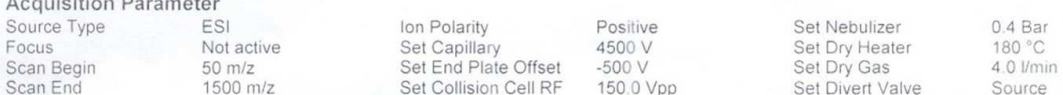

Scan End $\quad 1500 \mathrm{~m} / 2$

Set Collision Cell RF

$150.0 \mathrm{Vpp}$

source

Intens $\quad+$ +MS, $0.1 \mathrm{~min} \#(5)$

$5000-14341351$

4000

$3000-2{ }^{2}-2$

2000

1000

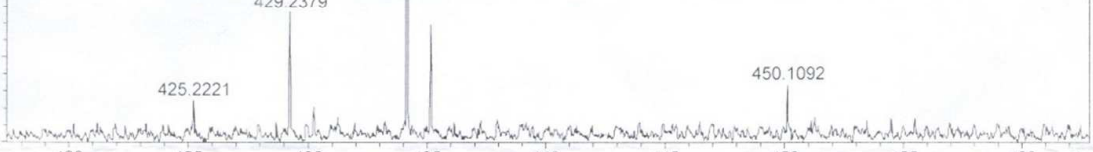

420

425

Meas. $\mathrm{m} / \mathrm{z}$ Formula

4341351

$\mathrm{m} / \mathrm{z} \quad$ err $[\mathrm{ppm}] \quad$ mSigma $\quad \mathrm{N}-$ Rule $\mathrm{e}^{-}$Conf

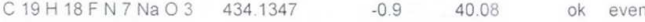

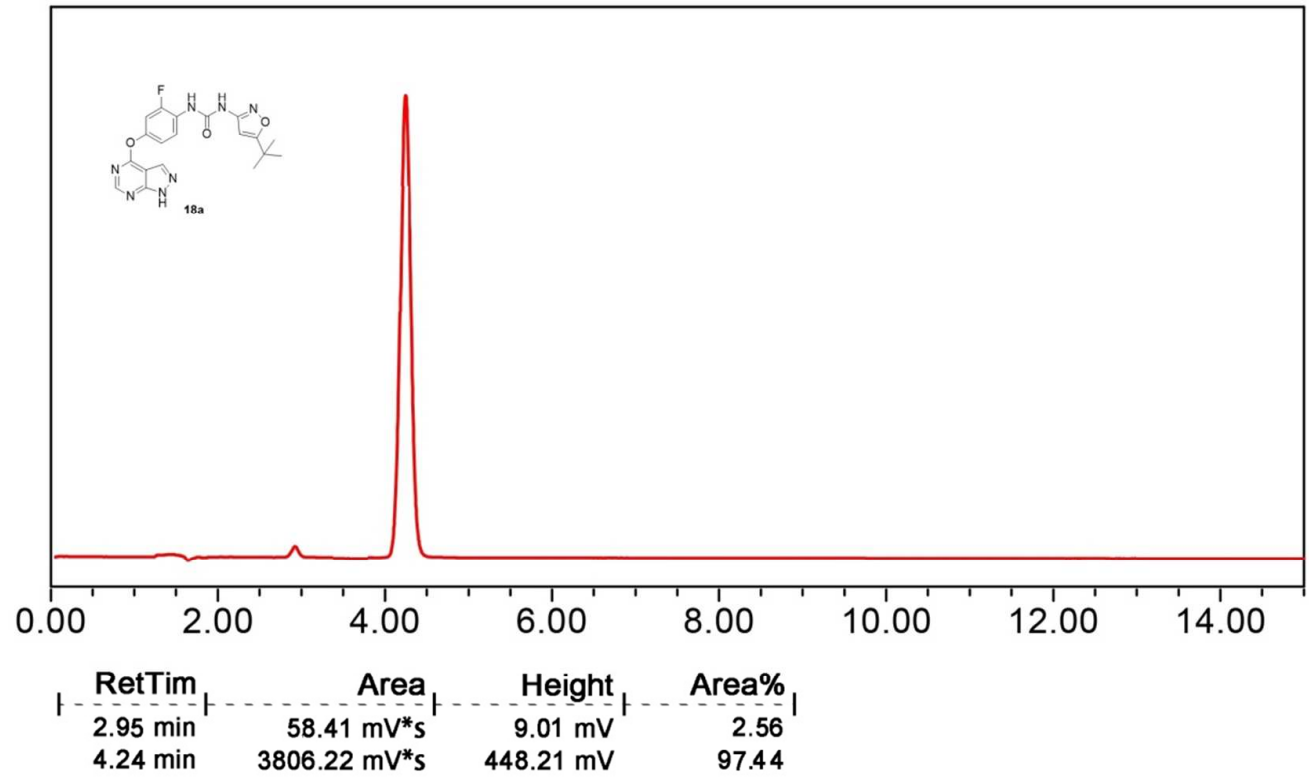


Figure S18. The ${ }^{1} \mathrm{H}$ NMR, ${ }^{13} \mathrm{C}$ NMR, HRMS spectra and HPLC chromatogram of compound $\mathbf{1 8 b}$.

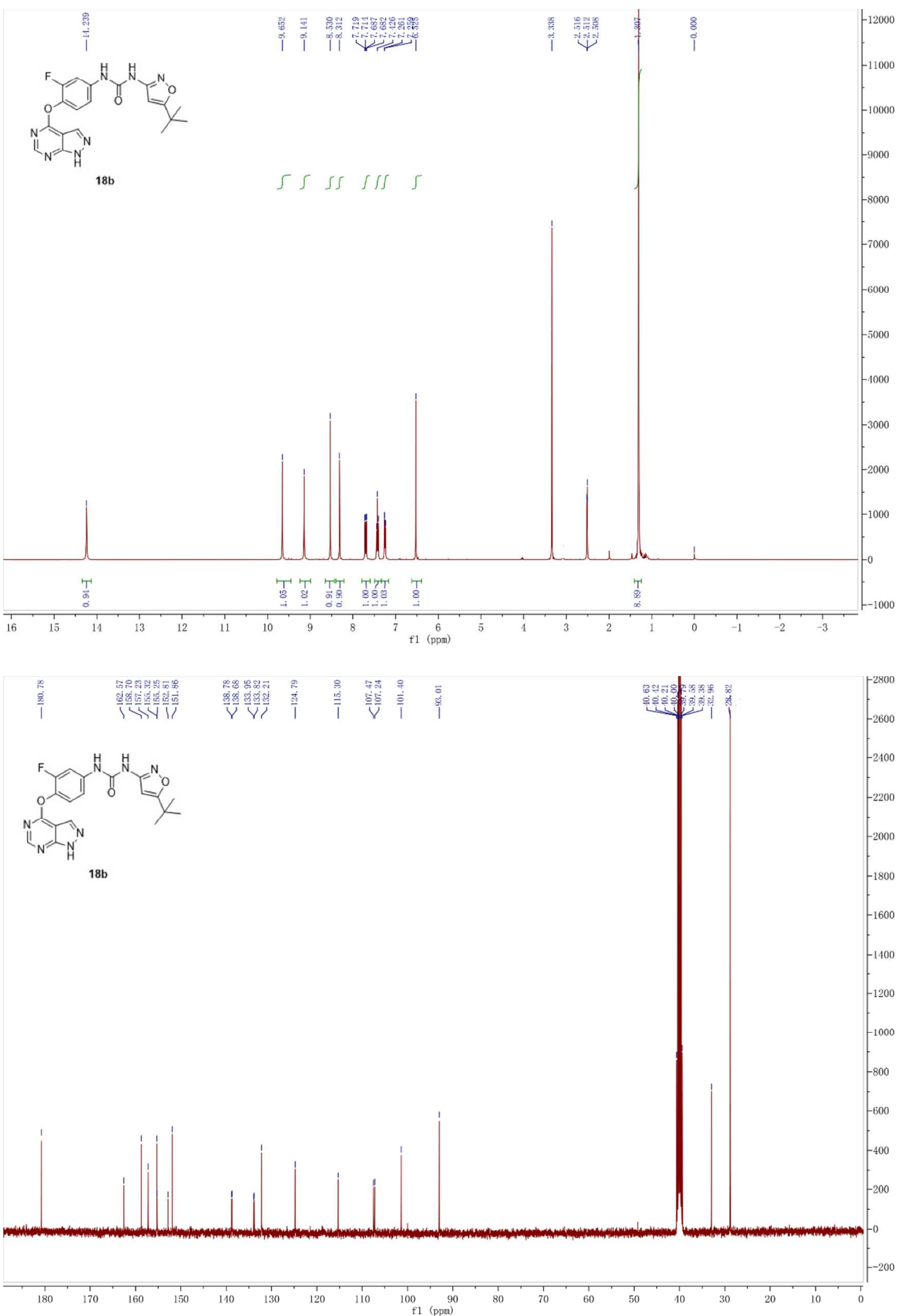



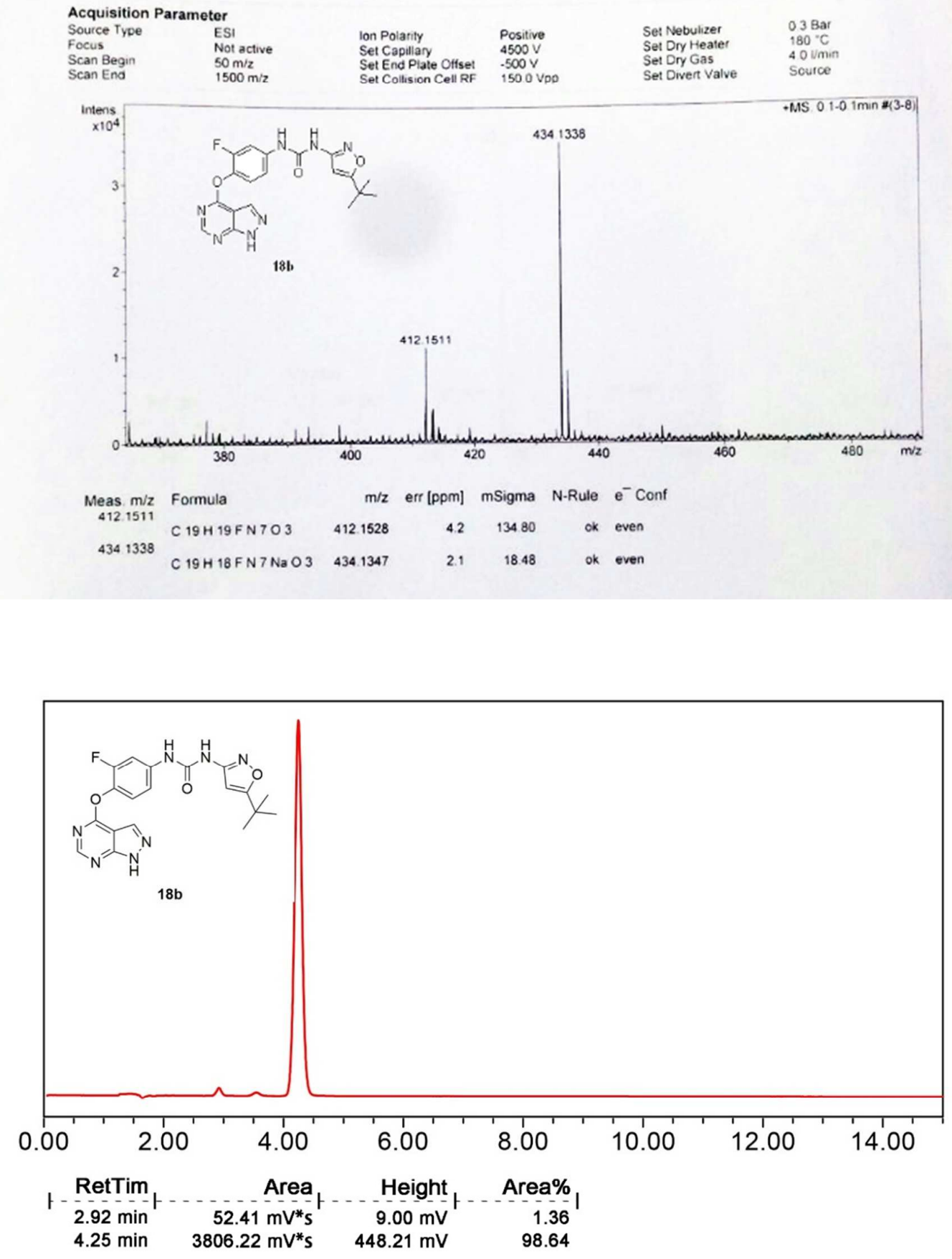
Figure S19. The ${ }^{1} \mathrm{H}$ NMR, ${ }^{13} \mathrm{C}$ NMR, HRMS spectra and HPLC chromatogram of compound 18c.

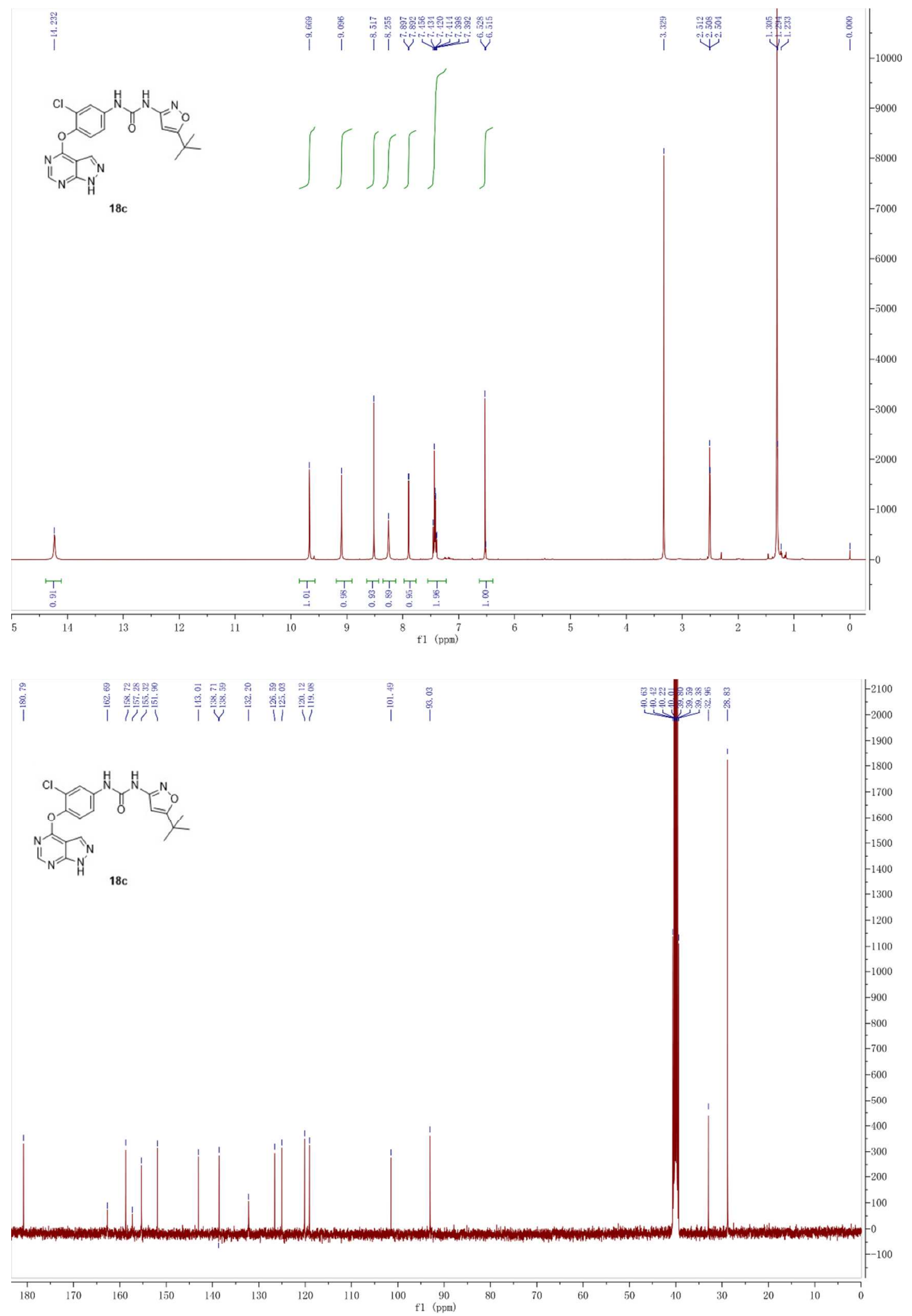



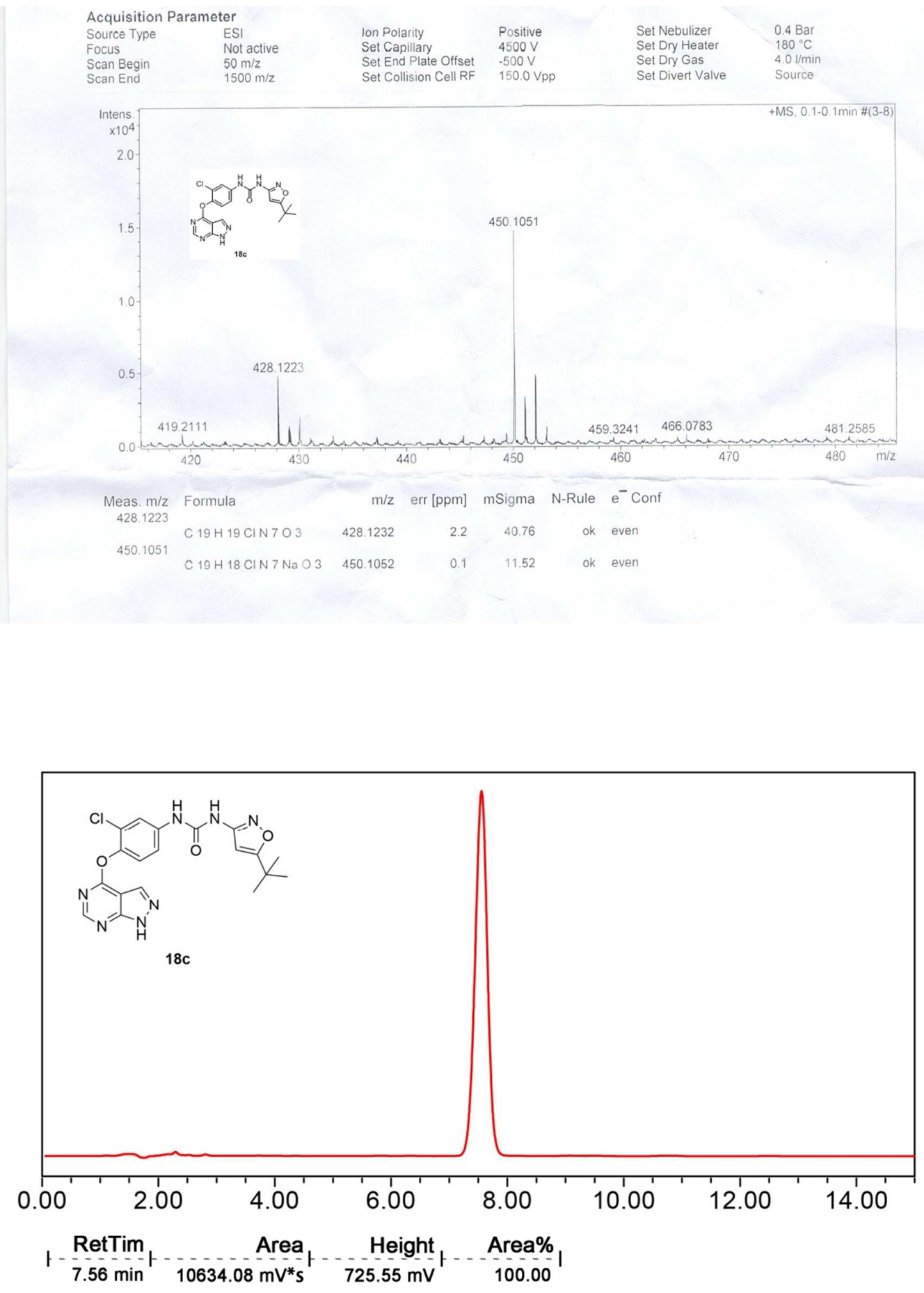
Figure S20. The ${ }^{1} \mathrm{H}$ NMR, ${ }^{13} \mathrm{C}$ NMR, HRMS spectra and HPLC chromatogram of compound 18d.
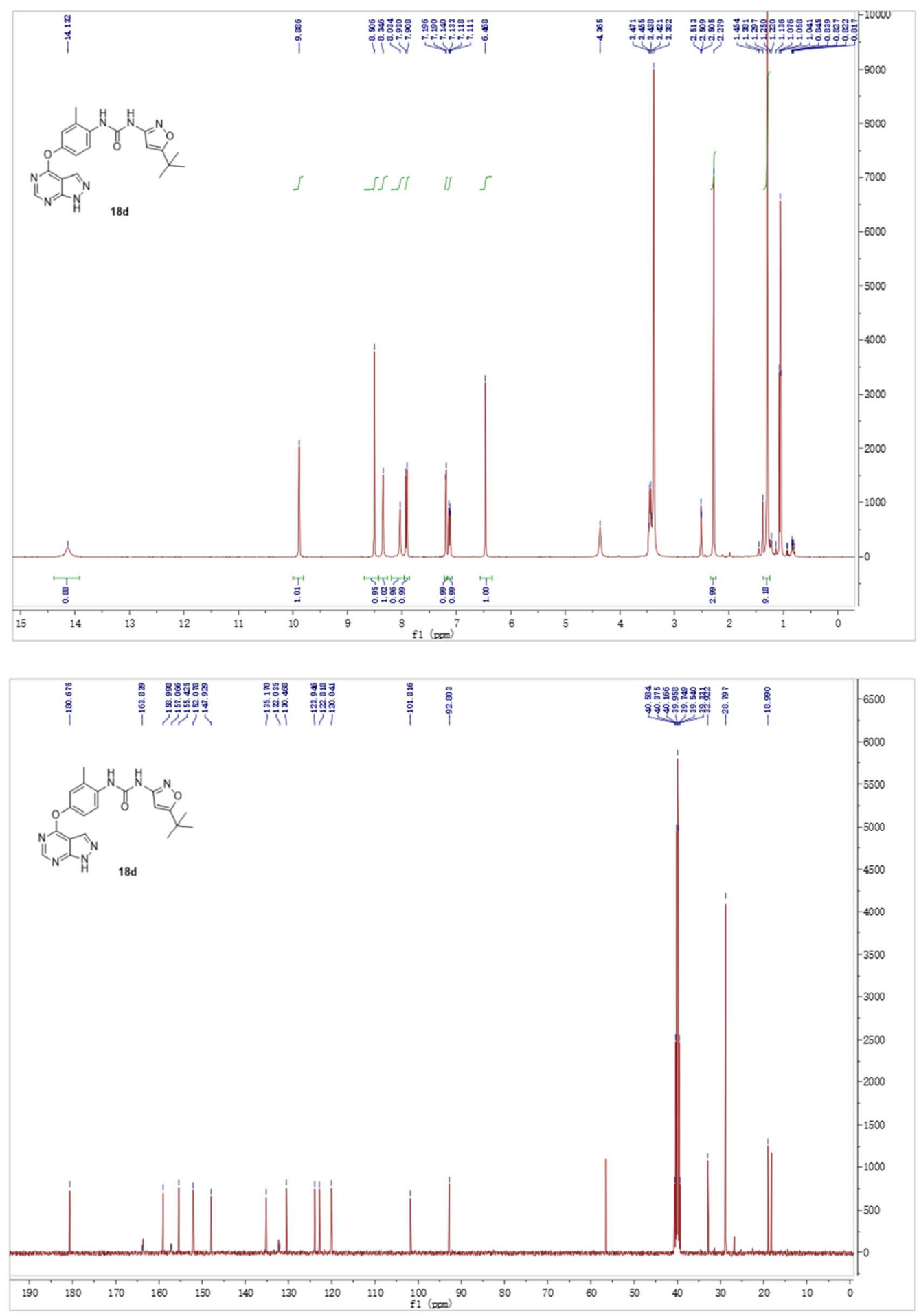

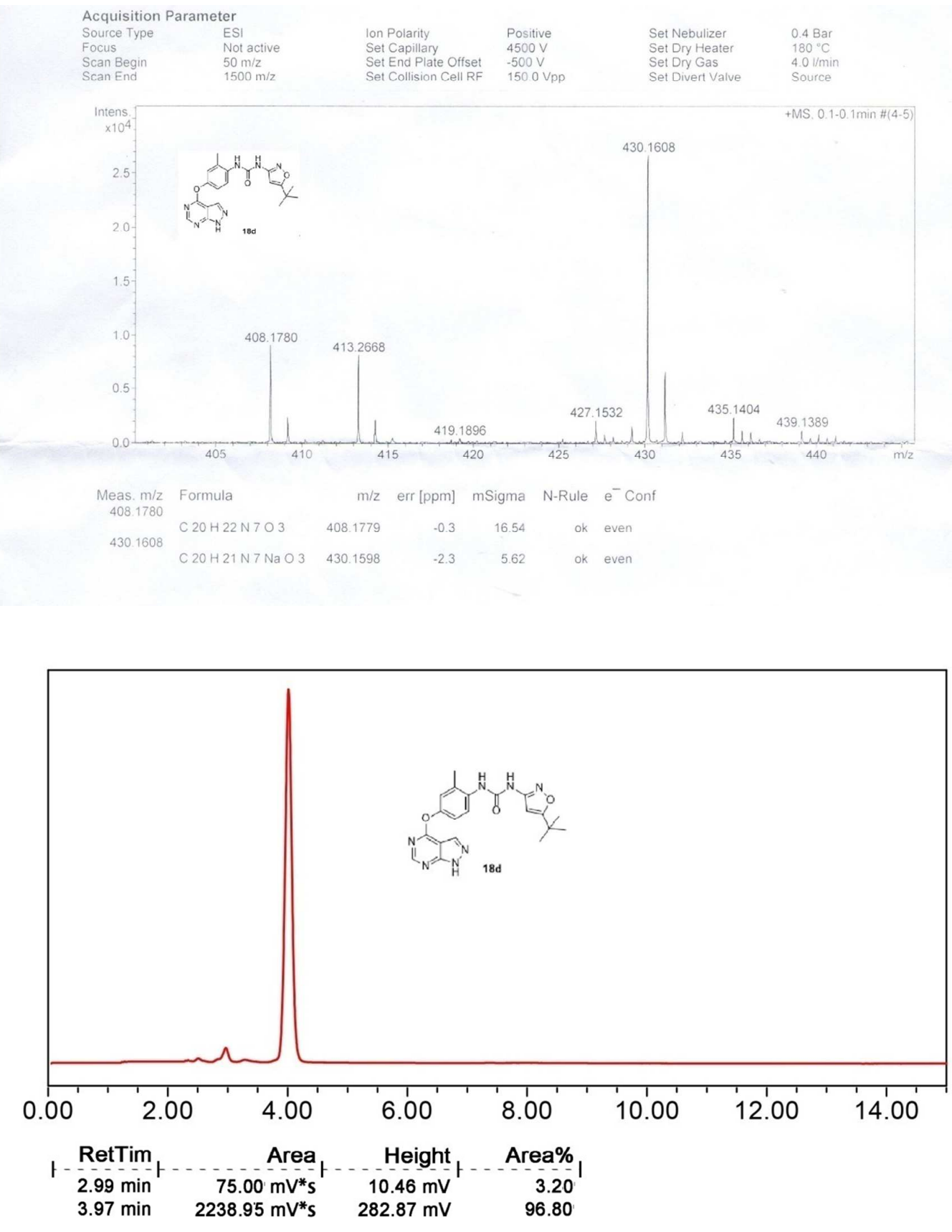
Figure S21. The ${ }^{1} \mathrm{H}$ NMR, ${ }^{13} \mathrm{C}$ NMR, HRMS spectra and HPLC chromatogram of compound $18 \mathrm{e}$.
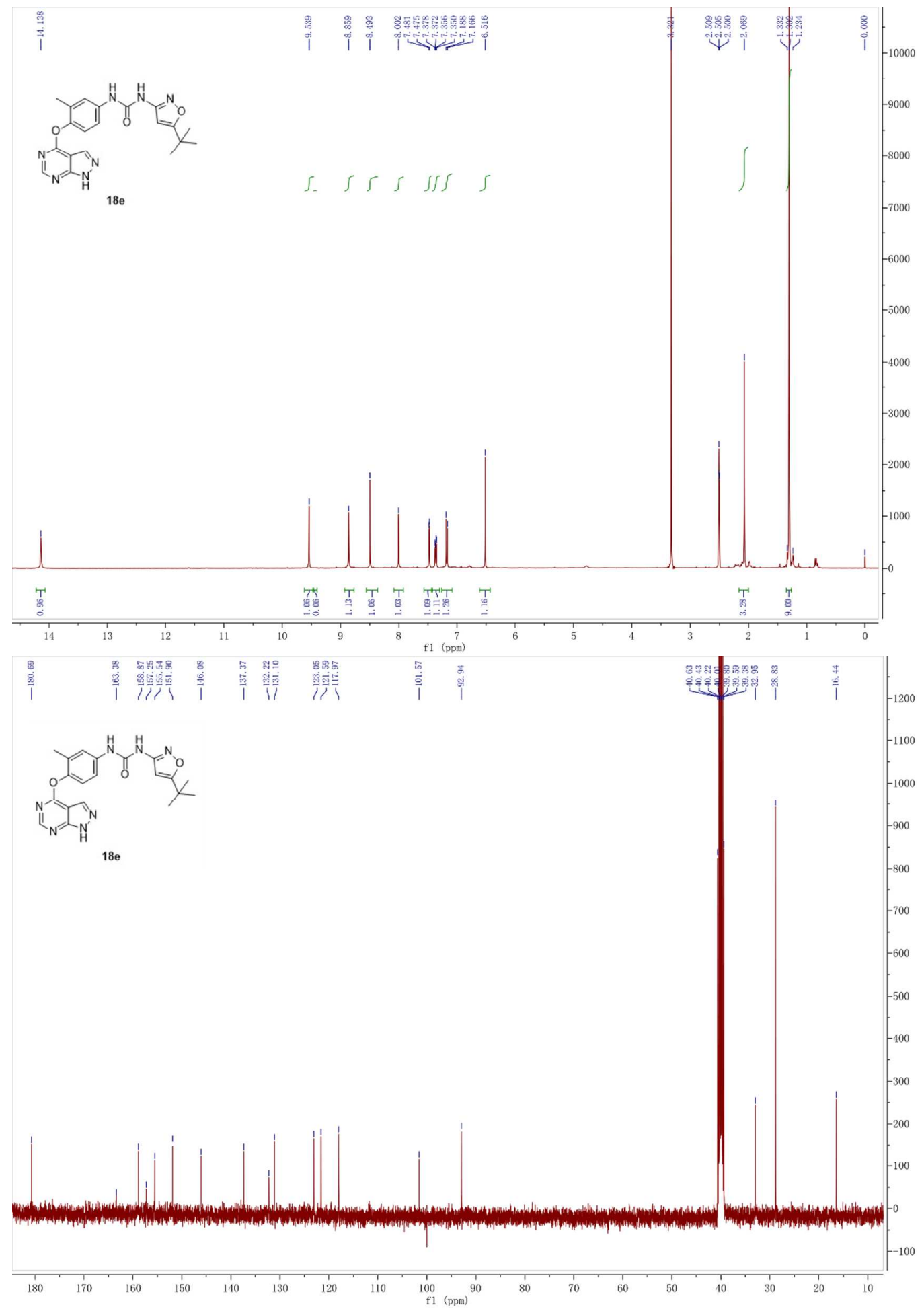

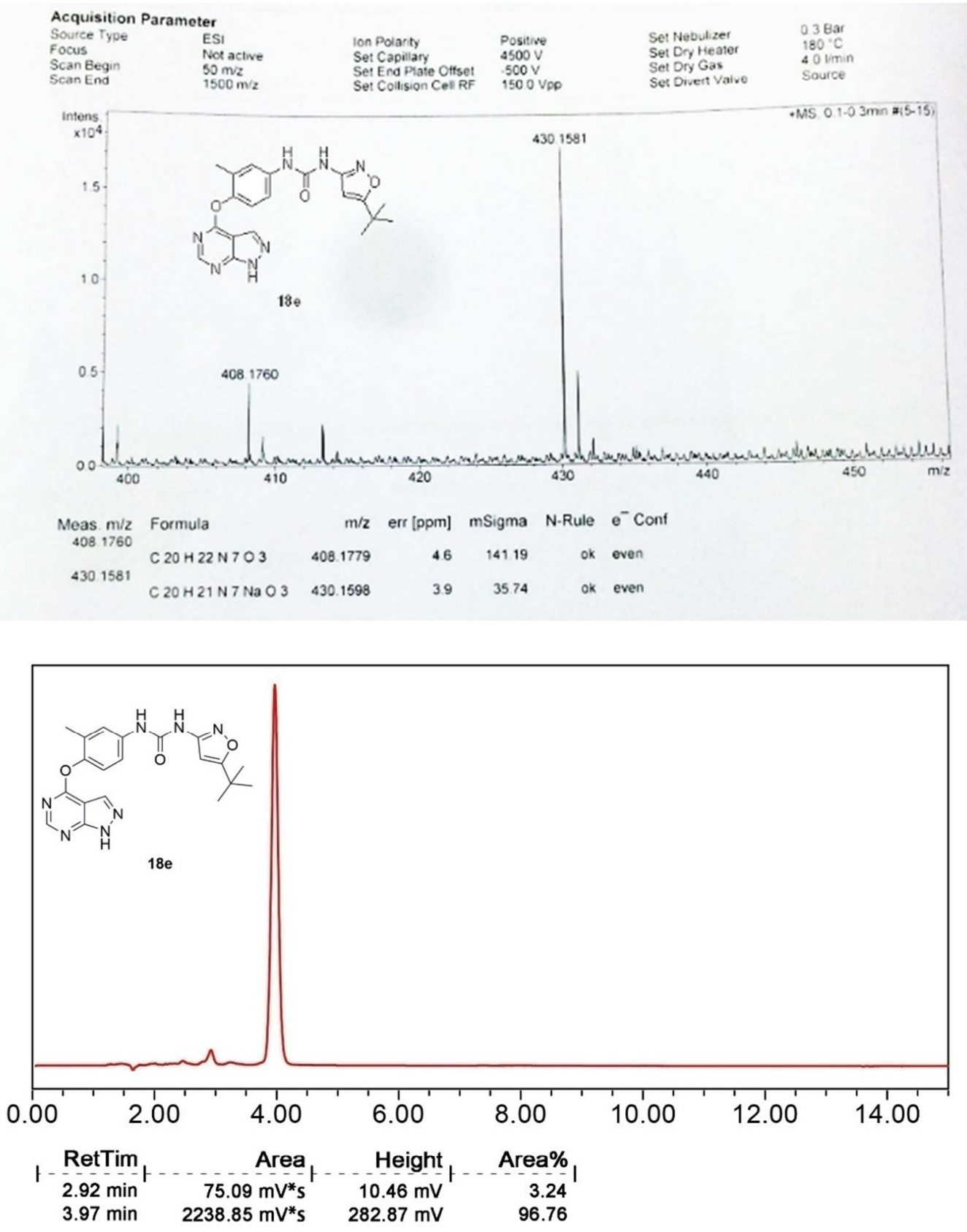
Figure S22. The ${ }^{1} \mathrm{H}$ NMR spectrum of compound 19a.

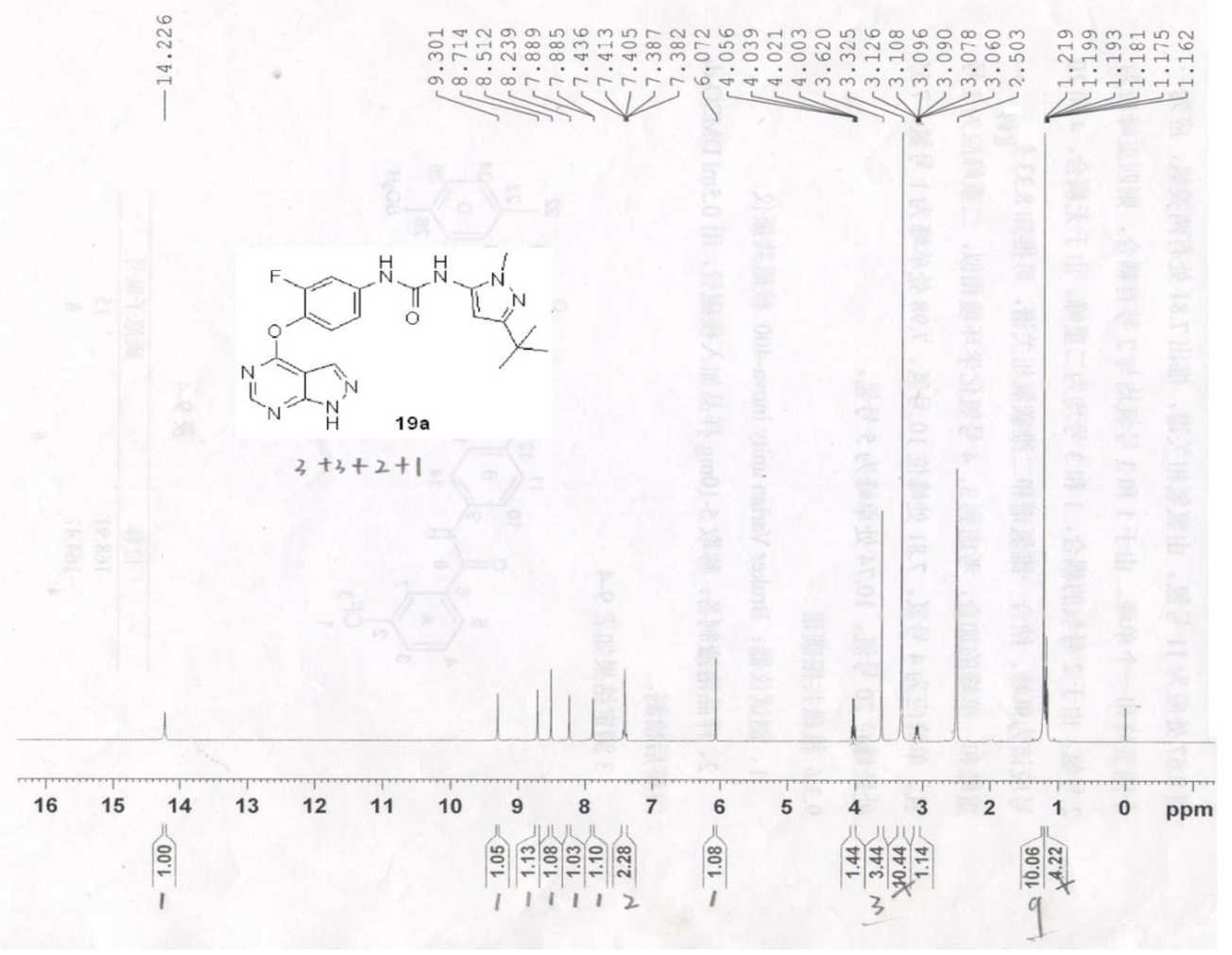


Figure S23. The ${ }^{1} \mathrm{H}$ NMR and ${ }^{13} \mathrm{C}$ NMR spectra of compound $\mathbf{1 9 b}$.
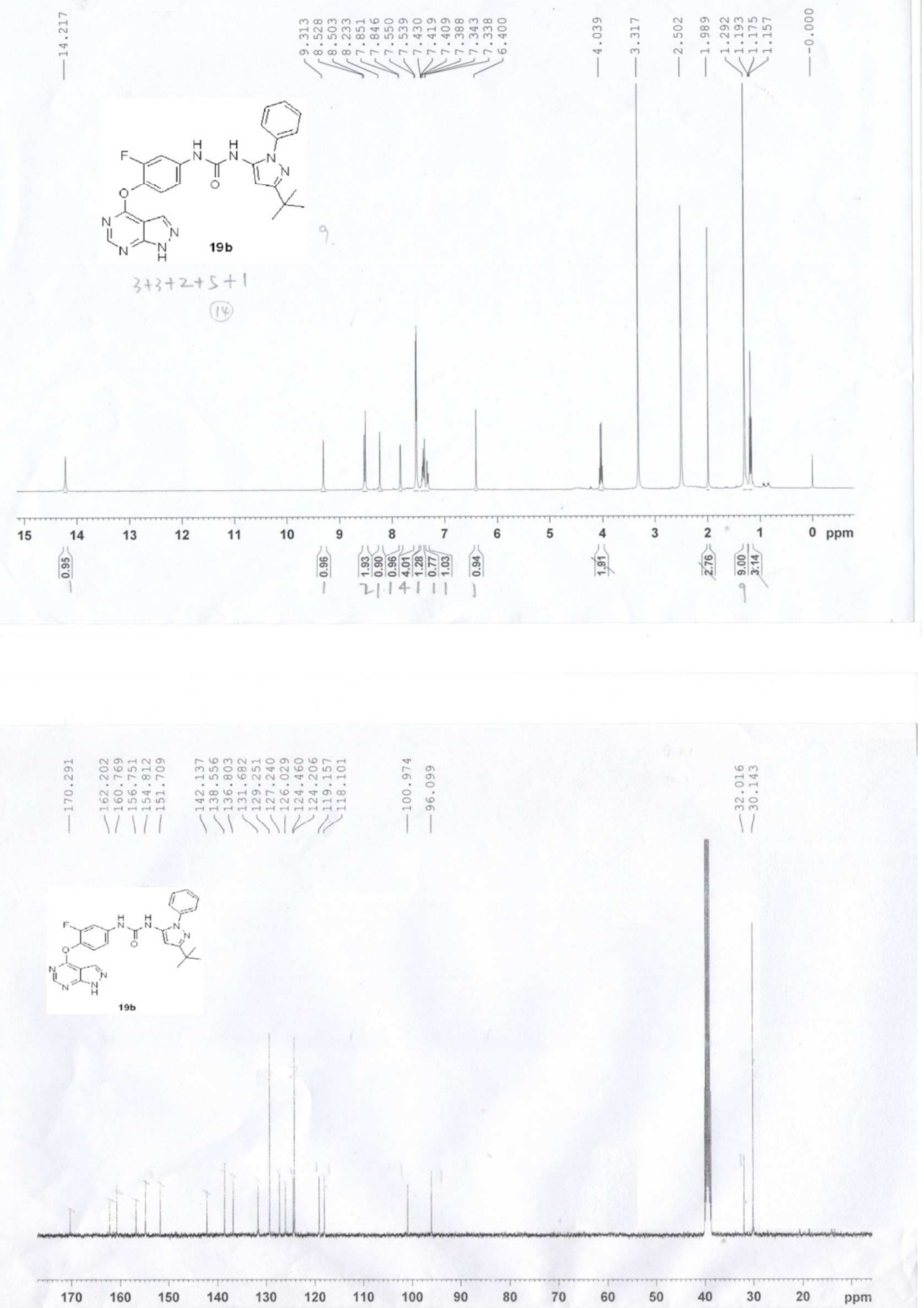
Figure S24. The ${ }^{1} \mathrm{H}$ NMR, ${ }^{13} \mathrm{C}$ NMR, HRMS spectra and HPLC chromatogram of compound 19c.

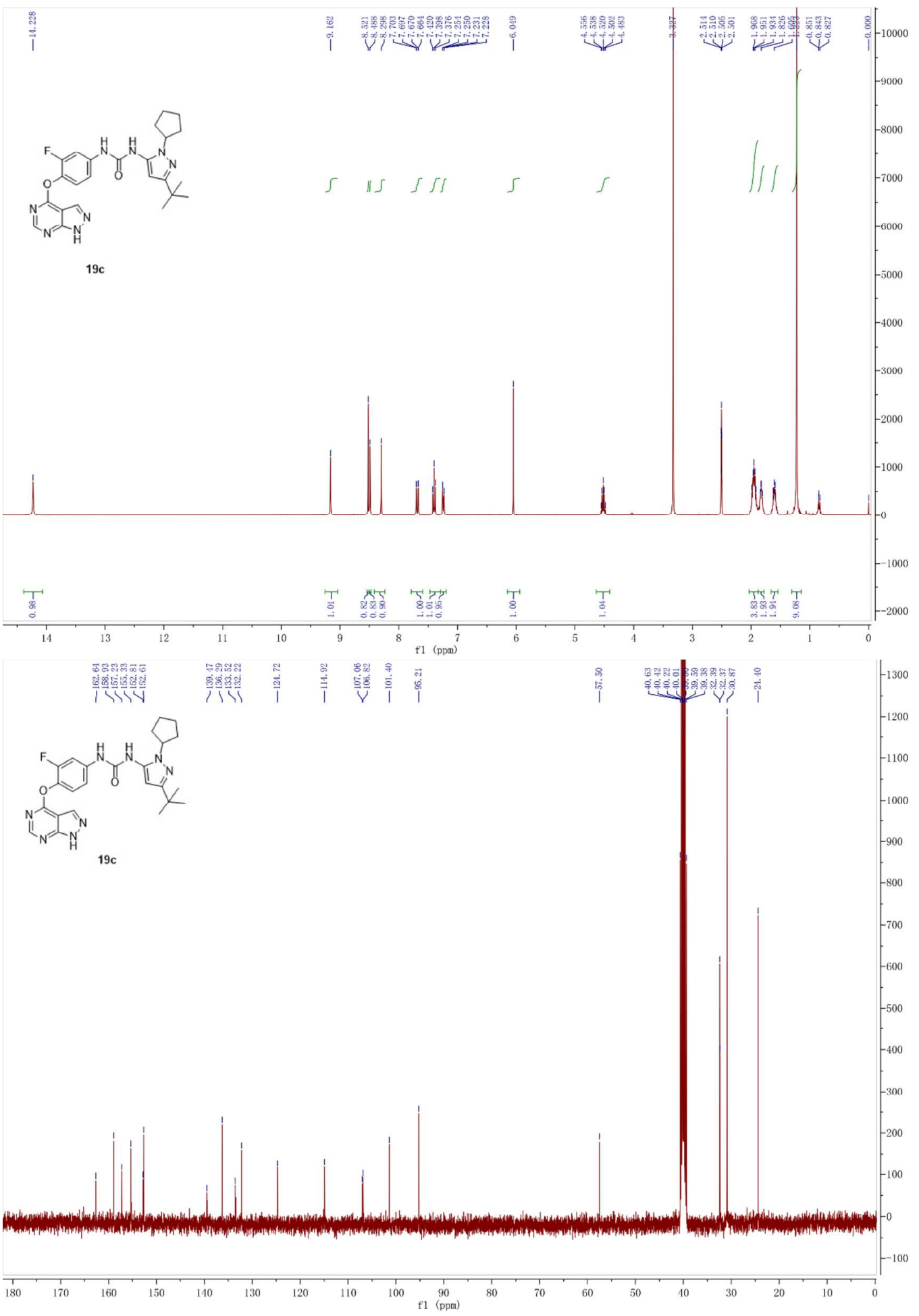




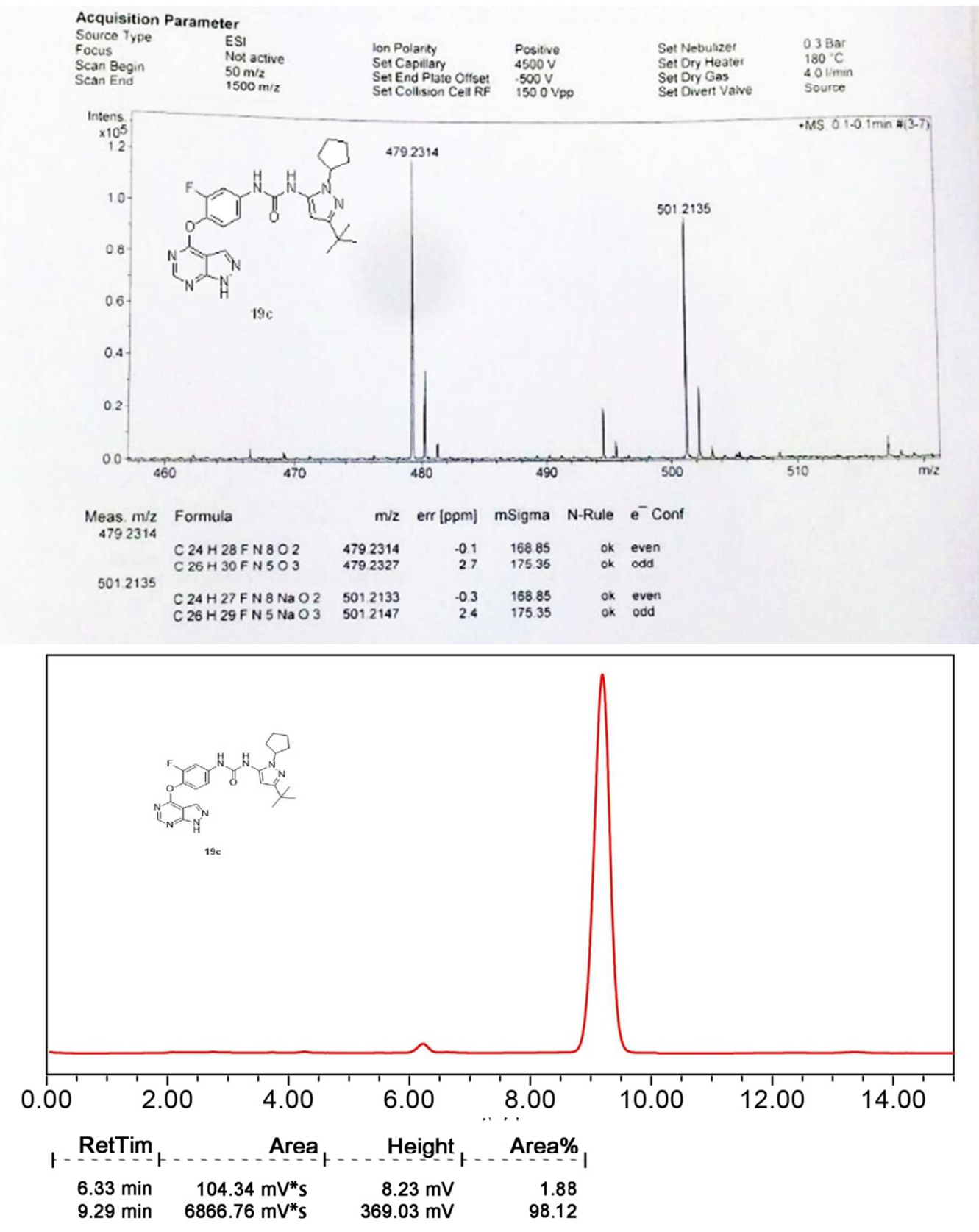


Figure S25. The ${ }^{1} \mathrm{H}$ NMR spectrum of compound 19d.
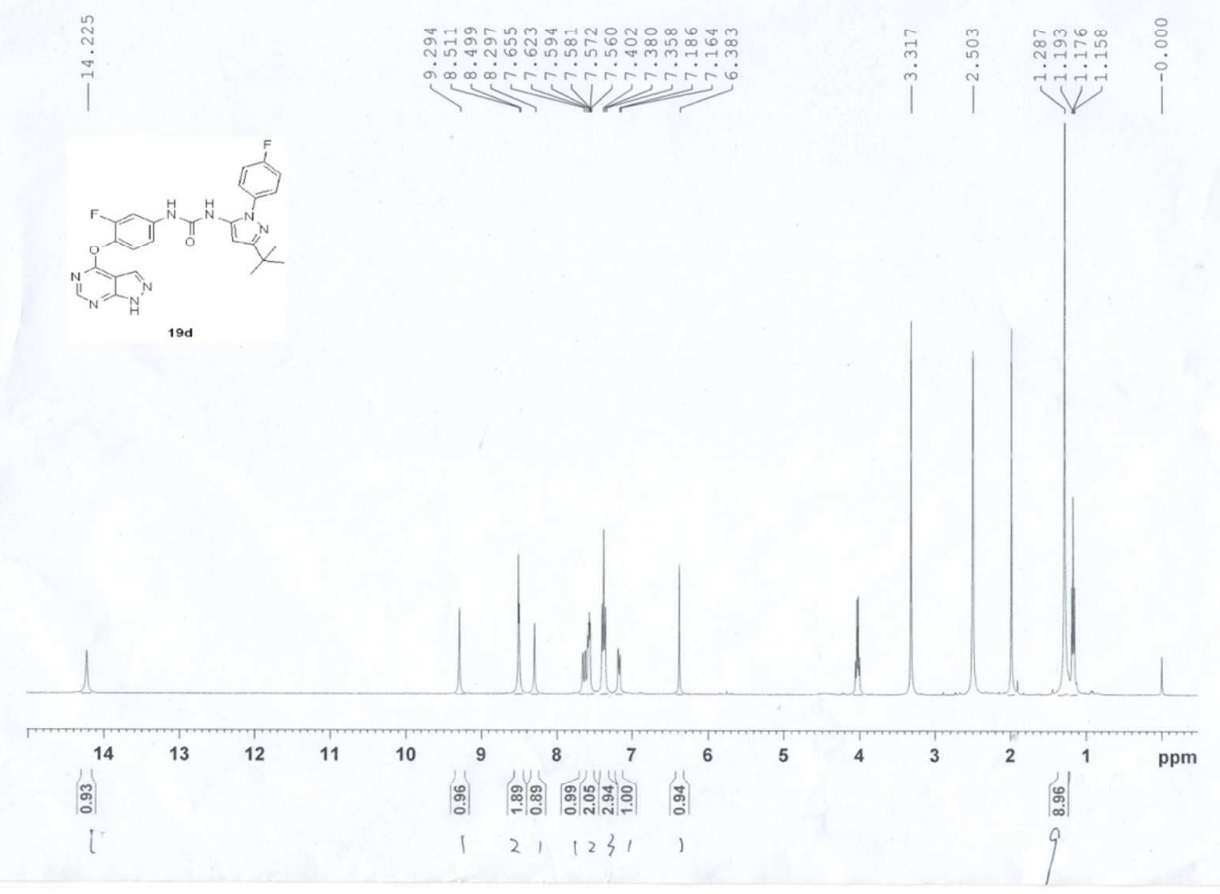
Figure S26. The ${ }^{1} \mathrm{H}$ NMR spectrum of compound 20.

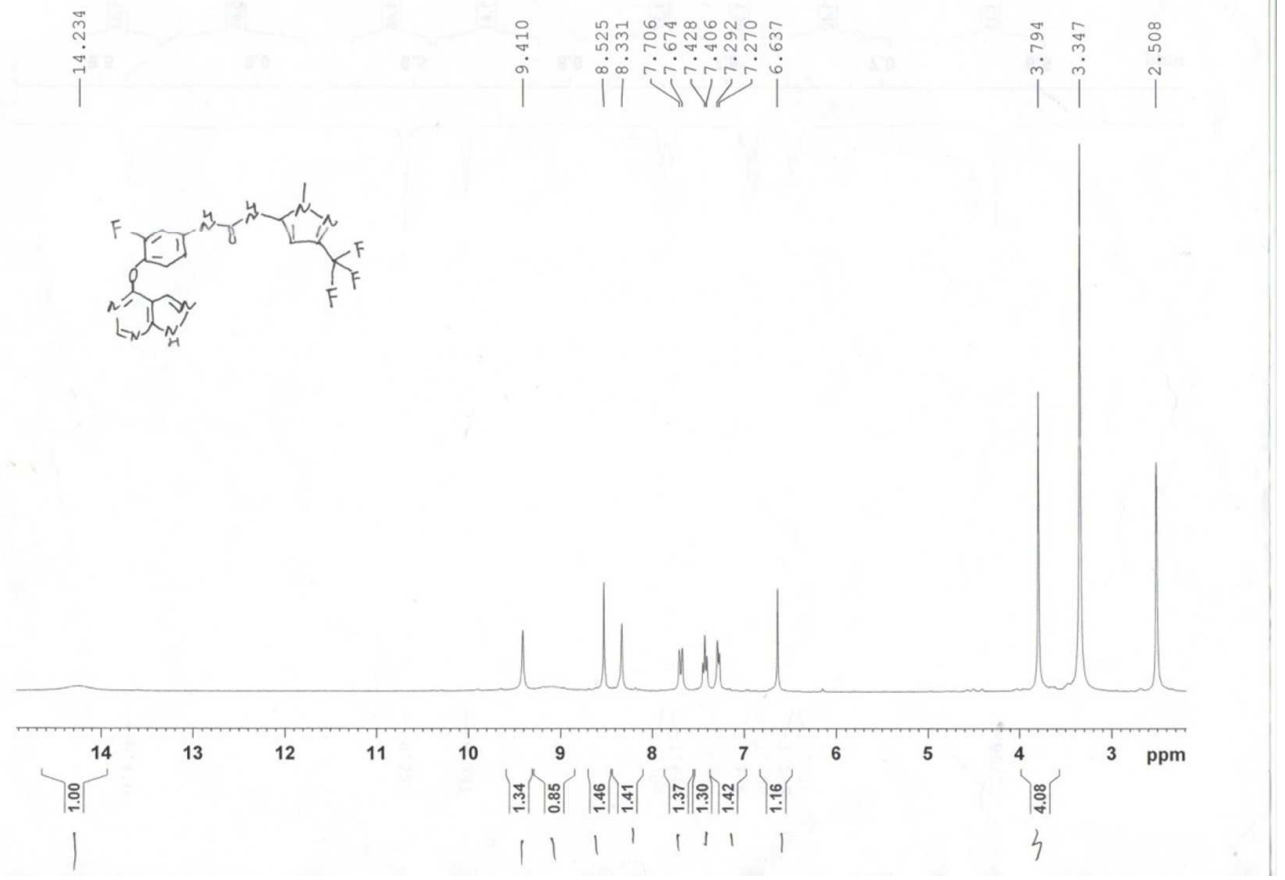

